\title{
On the Sustainability of Local Cultural Heritage Based on the Landscape Narrative: A Case Study of Historic Site of Qing Yan Yuan, China
}

\author{
Di Feng ${ }^{1,2, *}$, Shang-chia Chiou ${ }^{1}$ and Feng Wang ${ }^{2}$ \\ 1 Graduate School of Design, National Yunlin University of Science and Technology, Yunlin 64002, Taiwan; \\ chiousc@yuntech.edu.tw \\ 2 College of Fine Arts, Huaiyin Normal University, Huai'an 223001, China; edison-wangfeng@163.com \\ * Correspondence: fengdi165@gmail.com
}

Citation: Feng, D.; Chiou, S.-c.; Wang, F. On the Sustainability of Local Cultural Heritage Based on the Landscape Narrative: A Case Study of Historic Site of Qing Yan Yuan, China. Sustainability 2021, 13, 2831. https://doi.org/10.3390/su13052831

Academic Editor: Teen-Hang Meen

Received: 30 January 2021

Accepted: 22 February 2021

Published: 5 March 2021

Publisher's Note: MDPI stays neutral with regard to jurisdictional claims in published maps and institutional affiliations.

Copyright: (c) 2021 by the authors. Licensee MDPI, Basel, Switzerland. This article is an open access article distributed under the terms and conditions of the Creative Commons Attribution (CC BY) license (https:/ / creativecommons.org/licenses/by/ $4.0 /)$.

\begin{abstract}
As a feature of local cultural heritage, historical garden sites should not only focus on landscape sightseeing, but should also champion the sustainability of cultural heritage and promote the local community's wellbeing. This article uses the landscape narrative method to explore how the local public, with both professional and non-professional backgrounds, manages the cultural heritage and enhances its sustainability. Qing Yan Yuan is a historical garden site in Huai'an, Jiangsu Province, China, and constitutes the research area of this study. This article firstly conducts indepth interviews with local residents with non-professional backgrounds; then, it collects relevant information from professionals, such as introductions, comments, news, periodicals, etc.; finally, it adopts the content analysis method to decode, summarize and sort out accordingly. Through the analysis of landscape narrative data, this paper found that three cultural heritage value strategies are used by the public: (1) origin landscape narrative; (2) functional landscape narrative; (3) meaningful landscape narrative. The origin landscape narrative is the expression of a cultural heritage value of "past presentation"; the functional landscape narrative is a cultural heritage value of "place identity"; the meaningful landscape narrative shows a cultural heritage value of "future education"; all these together constitute the local public subjective conception of the sustainability of cultural heritage.
\end{abstract}

Keywords: landscape narrative; cultural heritage sustainability; heritage management; heritage value; local public

\section{Introduction}

The UNESCO 2030 Agenda for Sustainable Development proposes that cities and human settlements should be made to be inclusive, safe, resilient and sustainable, and emphasizes that further efforts should be made to protect the world's cultural and natural heritage [1]. Cultural heritage is the spiritual and cultural wealth of a place, the protection and development of which require the participation of its local people. This is because the local resident are not only the owners and frequent visitors of cultural heritage, but also the group of people who directly spread the value of cultural heritage. In addition, this view takes into account the Florence Charter claim that cultural heritage and landscape are the basic characteristics of communities, and should therefore be protected through traditional practices and knowledge transfer. In light of these factors, a sub-theme of Florence Charter was established, that is, sharing and experiencing the identity of communities through tourism and interpretation [2]. As Antrop (2005) found, oral history is a valuable tool with which the relationship between the landscape and the place can be revealed [3]. More importantly, there is a current call for bottom-up heritage protection and management methods, and these targets are mainly achieved through empowering local communities that aim to improve the community, in addition to the awareness of the heritage by the administrator of cultural relics and decision makers [4-6]. These methods are regarded as 
ways to improve community wellbeing and develop the sustainability of cultural heritage. However, how the local public can establish the value system of local cultural heritage through personal oral narration needs to be further studied.

Although studies on cultural heritage have mostly been derived from concepts and features which have been used to establish the relationship between people and the heritage environment, which have typically focused on the sense of place, identity, belonging, imagery, historical features, etc. [7-9], in these frameworks, the local people themselves have been conceptualized as being in a passive position. Under these circumstances, the public has often thought of cultural heritage as a property that belongs to UNESCO, instead of belonging to themselves [10]. In response to this, certain measures need to be taken to reverse the local public's perceptions, and sustainable cultural heritage management practices are human-centered [11], which can enhance the connection between the local public and the environmental space. Previous research on cultural heritage has been about local community participation in heritage management, factors which are partially involved in preservation practice [12-14]; however, in these research pieces, the opinions of local residents were not taken into full consideration. In the present research, the local community takes the roles of the owner and user in order to participate in the cultural heritage preservation process for sustainability through the landscape narrative. On the other hand, although research about the concept of landscape has been helpful for the public to understand the values and significance of cultural heritage [8,15], it does not specify how to implement. However, Lugeri and Farabollini (2018), based on the perspective of landscape ecology, found that landscape is the result of the interaction of many natural and cultural components, in addition to the expression of geological processes, and can be a "medium" that communicates earth sciences to the whole of society [16]. Therefore, the ways that the local community views preservation practices for cultural heritage through the landscape narrative requires further exploration. This article selects the historical garden site Qing Yan Yuan in Huai'an, Jiangsu Province, China, as a case study, based on the concept of landscape and cultural heritage preservation, which, combined with the common understanding of both experts and non-experts, aims to explore the management of cultural heritage from the landscape description experience framework to promote the local public's awareness of cultural heritage sustainability.

This article explores the local cultural heritage value in personal thinking via the interpretation of landscape information in daily life with the public, which establishes the awareness of empowerment for residents, who then become the main characters of local welfare development. As oral transmission from residents is a low-cost and economical way to preserve the sustainability of local cultural heritage, the specific means of implementation to promote the local public's sustainable practice of cultural heritage is from the inside out and bottom up. This spreads the cultural heritage value to surrounding residents and even to the next generation by taking advantage of the public's landscape language narrative and communication. In addition, language communication and dissemination of the local community can help the preservers of cultural heritage to discover how the residents transform the landscapes they perceive into personal values of cultural heritage. In addition, the local government does not need to invest heavily, but it should increase the awareness of the landscape theme together with cultural heritage to attract locals to visit, which forms the foundation of the management of cultural heritage sustainability. The structure of this article is as follows: first, it introduces the sustainable management practices of cultural heritage; second, it discusses how to integrate the landscape narrative into the sustainable development of local cultural heritage, and outlines the research process and deployment; then, it summarizes the local public's landscape narrative strategies and discusses how to incorporate them with cultural heritage sustainability; finally, the conclusion of the article are presented. 


\section{Literature Review}

\subsection{Cultural Heritage Sustainability}

\subsubsection{Cultural Heritage Value}

Cultural heritage is protected and managed because of its value. "Heritage value" provides an understanding of the status of heritage in the natural and cultural environment that includes special or historical features in the landscape, and refers to the meaning and value assigned by an individual or a group of people [17]. Similarly, cultural heritage can explain past traditions, provide clues, memories and commemorations, and enhance the cultural vitality of communities [10,18-20]. The Bula Charter proposes the concept of heritage "place", which enhances the understanding and identity between different nations that emphasize the connection between heritage protection and the place [21]. This shows that cultural heritage is helpful for local residents to make an association between the public and its historical significance, in addition the sense of identity, so that they understand the community identity, symbolic meaning, spirit of the place, social identity, etc. $[6,8,22,23]$. Furthermore, these forms of preservation and maintenance of cultural heritage have educational significance to contemporary society and the following generations because they maintain its historical and cultural significance. Antrop (2005) believes that the preservation of cultural heritage is the resurrection of the past, which helps to build future prospects [3]. Mei (2020), in analysis of the cultural relics of Gu-lang $\mathrm{Yu}$ Island, proposed that the value content associated with the people and art should be left to future generations, and comprises the landscape, art, history, society, education, emotion, etc. [24]. Qiu et al. (2020) divided the value cognition of residents and tourists into aesthetic, educational, spiritual, social, economic, and historical values that stimulate personal emotional attitudes and travel intentions through the traditional firing technology of Longquan celadon in Zhejiang Province [25]. Therefore, the value of cultural heritage not only has important social, cultural, economic, and environmental significance for contemporary society, but is also an effective educational tool. We need to protect and manage it well to pass the heritage to future generations, which is in line with the development goals of cultural heritage in the 2030 Agenda for Sustainable Development [6].

\subsubsection{Cultural Heritage Management}

The key to achieving the cultural heritage sustainability is normal preservation and management. Sustainable development is "development that meets the needs of the present without compromising the ability of future generations to meet their own needs" [26], which is currently the internationally accepted definition. In 2015, the United Nations adopted the "2030 Agenda for Sustainable Development" with Goal 4 aiming "to ensure inclusive and equitable quality education and promote lifelong learning opportunities for all", and Goal 11 to "make cities and human settlements inclusive, safe, resilient and sustainable". These goals provide support to cultural organizations to expand their influence on citizens [6]. In November of the same year, the "World Heritage Convention" incorporated the sustainable development perspective into its process policy [27], which shows that cultural heritage has great significance and value to humankind and society, and thus needs to be preserved and managed in a sustainable manner. Heritage management is an approach to identify the different elements that are needed to reconstruct human history, and mainly includes scientific and in-depth study of various tangible and intangible heritages, such as ancient ruins, architecture, culture, and traditions [28]. Scholars agree that the cultural heritage sustainability should be practiced by heritage management. Polat et al. (2019) believe that the heritage value should be protected and managed when improving social, economic, and environmental benefits [29]. Coincidentally, Basu (2020) emphasized that historical heritage needs to be managed in a sustainable manner to meet the requirements of present and future generations [28]. Jelincic (2020) proposed that heritage sustainability depends on factors such as funding, management, and manpower [30]. Therefore, heritage value-oriented management is an important practice form for the sustainability of local cultural heritage. Although many approaches exist to preserve and 
manage cultural heritage sustainability, the most important task is to establish a consensus on its value to ensure its successful implementation and maintenance.

\subsubsection{Local Public and Cultural Heritage Management}

Although cultural heritage value is an important factor in the legalization of heritage protection and management, as a promoter of the implementation of cultural heritage sustainability, it requires the common understanding of professionals and non-professionals. The 1992 Valletta Convention emphasized experts need to understand the cultural value of archaeological heritage, in order to help the public realize the heritage value for understanding the past [31]. Regrettably, cultural heritage organizations have adopted a top-down approach to heritage preservation, management, and evaluation, in which decisions are mainly made by senior management without careful consideration of the preferences of residents and tourists [32]. In addition, an importance assessment conducted by experts cannot capture the dynamics, iterations, and essence of social value [8]. More importantly, Harvey (2001), Evans (2002), Yung et al., (2020), and Grey (2020) found the protection of heritage should be based on the "community" to discuss the importance of local residents and tourists participating in heritage protection [33-37] because the public and experts agree on cultural significance [38]. This is because community residents are more familiar with local cultural relics than tourists and experts, and are more willing to protect their heritage [37,39]. In addition, UNESCO believes that the local public, as the main character of cultural heritage protection, is not limited to local residents and visitors, but public officials, non-governmental organizations, and various professionals are also key components. This fully shows that public participation in cultural heritage management contributes to the realization of the Sustainable Development Goals (SDGs) [40,41]. However, the cultural heritage management requires a consistent understanding of values of the local public in order to be implemented. Therefore, professionals and non-professionals should be incorporated into the management framework of cultural heritage sustainability that explores suitable practical methods.

\subsection{Landscape Narrative and Local Cultural Heritage}

\subsubsection{Landscape Narrative}

A "narrative" is a common means of expression by people who use stories to share their experiences or discoveries in life through their understanding [42]. Narrative analysis, also called linguistic or rhetoric analysis, defines a narrative as not only a statement of past things, but also an explanation of their understanding and meaning [43,44]. The focus is the content of actions, scenes, characters, methods, purpose, meaning, and situational structure, and previous studies have used these expressions of "life stories and dialogues" as research questions [45]. That is, narrative analysis is a model of looking at the world by the storyteller, who represents his experience using language as the expression tool. The authenticity and validity is not the key point, rather the focus is on how the narrator captures, presents, and interprets experience, paying attention to the past state, reason, and meaning presented. "Landscape" is derived from Western visual aesthetics, in which one's eyes "see" beautiful scenery and capture its aesthetic details, and store the image for long-term memory. Lothian (1999) regards landscape as a product of the bystander's mind that is a subjective form of existence [46]. Therefore, landscape quality can be regarded as a human construct that is explained through memory, association, imagination, and any symbolic perception. Although people see many of the same elements-houses, roads, trees, hills, etc.- - these facts should establish an association to form a unified concept [47]. That is, landscape is not only made up of things in front of you, but also exists in your mind, and the analytical focus is on the ways people organize notions by the essence of the landscape.

In landscape-based narrative research, in which actors demonstrate how to explain their past through storytelling, sharing, and listening to stories is the main focus [48-51]. For example, Chang et al. (2008) combined landscape narrative themes to increase students' 
understanding of preference for scenes [52]. Feng (2008) found that the use of storytelling in the garden formation process is helpful to establish a personal subjective conception of the place [53]. In terms of historical heritage protection research, Holtorf (2006) and van der Laarse (2010) discovered the cultural self-evidence and sense of identity of the narrator who used landscape language in an examination of the dynamics of the process of garden change [49,50]. Smith (2010) and Potteiger et al. (1998) studied people's explanations of their places with stories and historical facts, and found the integration of landscape narrative into the lives of residents makes the place real and natural [51,54]. Therefore, the study of cultural heritage with a landscape narrative is a way to find the past, from individual perception and cognition, which can help individuals and groups to induce a deep understanding of the cultural heritage value.

\subsubsection{Landscape Perspective on Cultural Heritage}

The landscape is an integral part of cultural heritage that can be assimilated into local heritage to make it easier for people to understand. In 1981, the Florence Charter proposed "heritage and landscape as human values", and proposed that landscape is an integral part of heritage. It is not only a dynamic memory of the past, but also a connection between the material and non-material from generations to generation [2]. The "European Landscape Convention" further affirmed that the landscape is "a part of the common heritage of Europe and should be protected and managed", and defines "the landscape is an area perceived by people" [55]. At the same time, research into the relationship between landscape and cultural heritage was also undertaken $[2,7,56,57]$. Ode et al. (2008) believe that landscape heritage is the activity or interaction between man and nature that focuses on the human experience of the landscape, in addition to the perception and characteristics of the landscape [58]. Some researchers regard the landscape as a "landscape-like substance", which triggers the stimulation of the body's organs and the recognition of location [7,59-61]. This kind of landscape and cultural heritage research is based on perception and cognition through personal understanding of landscape information, which combines with past experience, future expectations, and social and cultural conditions to give cultural heritage meaning. Moreover, the evaluation and appreciation also change significantly so that different people "see" different scenery in the same place [62]. Therefore, the consensus on the cultural heritage value with the public needs to be established through the process of understanding landscape. However, the landscape narrative is a collection of personal experiences of the place, which can help us discover how the individual organizes the process of perception and cognition of values. In addition, the study of cultural heritage based on the concept of landscape provides an expert perspective. For example, Lowenthal (1997) emphasizes the three attributes of landscape as heritage: materiality, landscape as a cultural relic container, and stability [56]. Xia and Chiou (2016) proposed the landscape model of cultural heritage preservation: (1) landscape as the external foundation; (2) landscape as the inner physiological sense; (3) landscape as the core culture; and (4) landscape as the spiritual place [8]. Although these studies expand the internal connection between landscape and cultural heritage, they are mainly used by the upper class with a professional background. Mascari et al. (2016) established an information interaction system model between heritage, landscape, and culture to only be used by those with professional backgrounds [63]. Cocks et al. (2018) found that the protection of cultural heritage emphasized the well-educated upper class when studying the local cultural landscape of South Africa [64]. Even in the protection of heritage and identity with local characteristics, natural and cultural heritage mostly prioritized "expert" evaluation [65-67]. This is not conducive to the landscape form that is the sustainable development of cultural heritage in the long run. Therefore, the study of cultural heritage from the landscape perspective needs to involve both professionals and non-professionals in the framework. 


\subsubsection{Landscape Narrative Integration into Local Heritage Management}

Integrating the landscape narrative into the management of cultural heritage can enhance the local public's awareness of empowerment while contributing to the practice of cultural heritage sustainability. Boley and Johnson (2016) found that empowerment is often characterized by residents perceiving themselves as being more connected to the community and willing to work together toward common goals [68]. Guilfoyle et al. (2019) emphasized the empowerment that fosters relationships and connections with cultural landscapes and heritage [69]. More importantly, the local public has the rights and obligations of heritage management in the practice of cultural heritage sustainability, which can preserve the local spirit for future generations. For specific public participation methods, Sanoff (2000) carried out sorting using approaches such as the awareness, group interaction, game, indirect, and open methods [70]. Yun and Prott (2016) found the nation of Qiang decided what to record and produce, and manufactured an A'er archive and a dialogue manual in the process of preserve the cultural heritage of A'er Village in Sichuan, China [12]. Jones (2017) believes that qualitative interviews and ethnographic evaluations of non-professionals, combined with community participation in practice, can better result in heritage protection and management [9]. This is the daily experience of "ordinary people" who can create a local heritage "story" to obtain their identity [71], and present the diversity of local cultural heritage.

The public's perception of cultural heritage value is consistent with the narrative of connecting experiences to thinking processes, which comes from the processing of spatial environmental information [59] that is interpreted by individuals. In this field, Riessman (1993) divided the primary experience of "representation of the world of experience" into five levels: attending the experience, telling the experience, transcribing the told experience, analyzing the told experience, and reading the re-expression of the experience [44]. In addition to empirical attention, the landscape narrative also improves aesthetic feelings and spatial experience of residents. The landscape is an important part of European cultural and natural heritage, according to research on ability of landscapes to tell local stories while enhancing the identity and overall value [2,72]. Therefore, citizens who used the landscape narrative to construct cultural heritage values empower the local cultural heritage, and promote the public initiative for storytelling for education.

Based on the above discussion, we address the questions of how to mobilize the local public's awareness of empowerment with cultural heritage value through landscape interpretation, to encourage them to actively participate in the sustainable management of cultural heritage. In this article, we believe that a consensus among the local public will help with putting cultural heritage sustainability into practice. Therefore, we examine the backgrounds of professionals and non-professionals, in addition to the local public. The historical garden site of Huai'an in Jiangsu Province-Qing Yan Yuan was selected as the research case. In addition, the landscape narrative method was used to collect public opinions on heritage interpretation, which explore how individuals or groups establish a notional system for the local cultural heritage value (Figure 1).

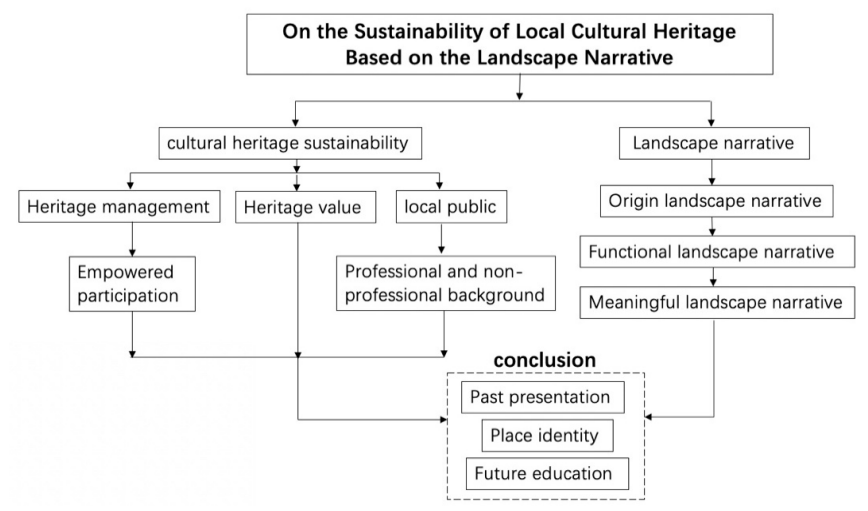

Figure 1. Structure of this study. 


\section{Materials and Methods}

\subsection{Study Area}

As the purpose of this article is to investigate how the local public spread the value of cultural heritage through landscape narratives, it is necessary to satisfy the landscape function and cultural heritage significance in the selection of a case study. The research area of this article is Qing Yan Yuan, which is located in Huai'an City, Jiangsu Province, China. This was originally the Cao-yun Management Center (also known as Grand Canal, or Water Transport Management Center) in Qing Dynasty, and is now a cultural relic protection object in Huai'an and China. As shown in Figure 2, the Chinese government has set up a monument of cultural heritage in Qing Yan Yuan. "Shuo wen Jie zi" translates as "Cao, water turns to valley. One said: it is boats for people to ride on." From this, we know that "Cao" is a kind of water activity that refers to boating on the water. Cao-yun is the national lifeline that balances the difference of the economically centered South and the politically centered North since the excavation of the Beijing-Hangzhou Canal (also known as Grand Canal) in the Sui Dynasty. This established a series of water transportation management institutions during the Ming and Qing Dynasties [73-75]. Huai'an was once the transfer station due to its superior geographical location in the Ming and Qing Dynasties, when it acted as a water transportation command center, a river treatment center, a water ship management center, a water grain shipping center, and a Huaibei salt transportation distribution center [74-76]. The Cao-yun Management Center (called Qing Yan Yuan today and in the following text) served as the key sector of the Beijing-Hangzhou Canal, where the Canal Governor-General worked to encourage water conservancy to ensure the smooth flow of the canal and the safety of the people [75]. The task was arduous, and critical to the survival of the country's economic lifeline and local people's livelihood. Thus, every Canal Governor-General lived at the case study area because of the importance of his work. In the seventeenth year of Kangxi (1678), the first Canal Governor-General, Fu Jin, rebuilt the previous yamen (Chinese ancient government office) to form Qing Yan Yuan when he was stationed in Huai'an [75]. Subsequently, Qing Yan Yuan was changed from the Cao-yun Management Center to the Jiangbei provincial commander-in-chief, Jiangbei Governor's Office, Jiangbei Military Command, Huai-yang Government Office, and local government offices, was finally became a place for people's leisure and a memorial [77].

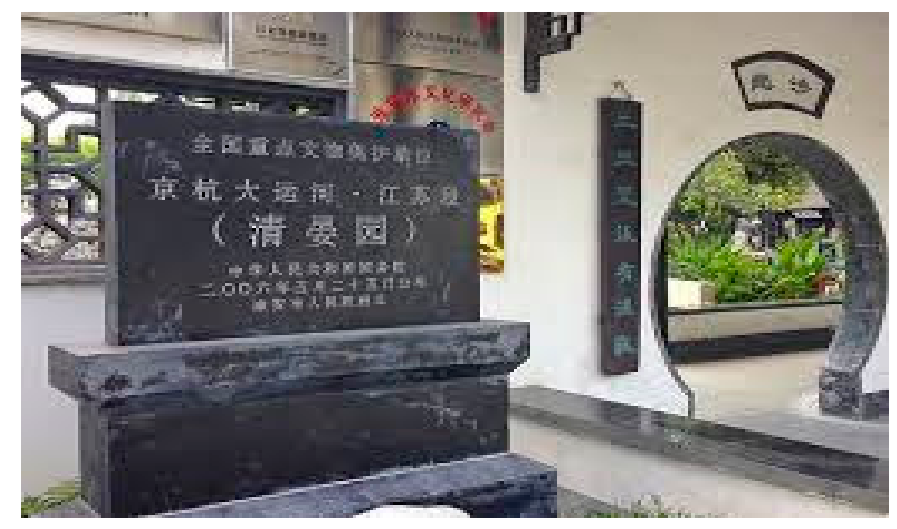

Figure 2. Qing Yan Yuan as a Cultural Heritage Protection Object.

This research aims to explore cultural heritage sustainability in view of the local public's landscape narrative. Qing Yan Yuan is a historical garden site in Huai'an which embodies the history of Cao-yun Management Center and the Beijing-Hangzhou Canal, which is an important part of the Huai'an Cultural Heritage. More importantly, it is a comprehensive historical site that includes architecture and gardens. As shown in Figure 3, the site allows visitors to overlook ancient buildings, lakes, and plants in Qing Yan Yuan. Therefore, we chose Qing Yan Yuan as the study area to allow us to collect "landscape stories" from the public to carry out the subsequent research. 




Figure 3. Panorama of Qing Yan Yuan.

\subsection{Research Methods}

This study takes the landscape narrative of the local community as the main research content, with the aim of exploring the expression of cultural heritage value in residents' vocabulary while listening to the description of the local population. We used an inductive qualitative method [78,79], similar to that in many related studies that analyze landscape narratives [49,51-54]. Huai'an, Suzhou, Hangzhou, and Yangzhou were once known as China's four major cities in the Ming and Qing Dynasties [73,75], when Huai'an was the Cao-yun Management Center in China's history. The economy of Huai'an plummeted after the decline of the Beijing-Hangzhou Grand Canal, which left only its glorious history and the culture of the Huai'an. However, the canal contributed to the attitude of the public, who introduced Huai'an history and culture to others; thus, the ancient Huai'an government office, Qing Yan Yuan, and Water Transport Museum have become oral representatives of the cultural heritage. Jones (2017) proposed that qualitative interviews and rapid ethnographic assessment are more suitable for assessing social value [9]. Although the content of the oral landscape is based on residents' preferences and interests, which has some limitations, it still reflects personal value orientation. Therefore, the researchers explored residents' understanding of these landscape values by combining interviews with listening to the oral landscape content of Huai'an residents. Both professionals and non-professionals are the research objects of this article. The non-professionals are mainly local residents of Huai'an, and the professionals are the authors of the published periodicals, books, reports, reviews, and introductions relating to Qing Yan Yuan. We followed the principle of letting the "data speak" [80] and integrated the professional and non-professional landscape narratives, and the content analysis method was adopted to gradually deduct and summarize the research topics.

\subsection{Data Collection}

The interviewees of this study include both the aborigines and long-term residents. Interviews were conducted to present Huai'an residents' linguistic descriptions of the local landscape, which includes non-professionals. These residents are merchants living within $500 \mathrm{~m}$ of Qing Yan Yuan and residents who are more than $3 \mathrm{~km}$ away but frequently visit the garden. First, interviews with non-professionals were stopped after no new content appeared; finally, there was a total of eight interview subjects who were familiar with Qing Yan Yuan, and visited and experienced it. The interview subjects included two merchants around Qing Yan Yuan (lived for more than 10 years); two tourists in the park; two local residents of Huai'an; and two residents who worked and settled in Huai'an (over 6 years). Second, the data of professionals was taken mainly from scholars who published research on the theme of Qing Yan Yuan, including tourism website introductions, tourism evaluations, news reports, literature, and periodicals. In these data, we used the keyword "Qing Yan Yuan" in searches for eight documents in the China National Knowledge Infrastructure (CNKI), and 10 travel introductions to Qing Yan Yuan, such as mafengwo.com, tourist attraction reviews, jstour.com, qjtrip.com, lvmama.com, ctrip.com, tuniu.com, bytravel.cn, ourjiangsu.com, and wenming.cn; one copy of the Qing Yan Yuan 
tour guide; 83 reviews on Ctrip and four comments on Tianya Tieba. In addition, we included 13 Qing Yan Yuan news reports from bilibili.com, toutiao.com, gmw.cn, and huaianmh.com. A final collection of data totaled 149,383 words and 87,096 sentences that described the landscape of Qing Yan Yuan was screened when the topic of these articles were summarized and analyzed (Table 1).

Table 1. Summary of Data Sources.

\begin{tabular}{|c|c|c|c|}
\hline \multicolumn{2}{|c|}{ Data Source and Code } & Data Form & Quantity \\
\hline \multirow{2}{*}{ Cnki.Net (J) } & Journal (01-06) & publish an article & 6 articles \\
\hline & Books (07-08) & Publishing books & 2 books \\
\hline \multirow{11}{*}{ Tour Introduction (T) } & mafengwo.com (01) & Website Introduction & 1 article \\
\hline & Tourist Attractions Reviews (02) & Website Introduction & 1 article \\
\hline & jstour.com (03) & Website Introduction & 1 article \\
\hline & qjtrip.com (04) & Website Introduction & 1 article \\
\hline & lvmama.com (05) & Website Introduction & 1 article \\
\hline & ctrip.com (06) & Website Introduction & 1 article \\
\hline & tuniu.com (07) & Website Introduction & 1 article \\
\hline & bytravel.cn (08) & Website Introduction & 1 article \\
\hline & ourjiangsu.com (09) & Website Introduction & 1 article \\
\hline & wenming.cn (10) & Website Introduction & 1 article \\
\hline & Guide words (11) & word document & 1 article \\
\hline \multirow{2}{*}{ Tourism Evaluation (E) } & ctrip.com (01-83) & Attractions Evaluation & 83 articles \\
\hline & bbs.tianya.cn (84-87) & Post a comment & 4 articles \\
\hline \multirow{4}{*}{ News Report (N) } & bilibili.com (01) & media reports & 1 press release \\
\hline & toutiao.com $(02-05)$ & media reports & 4 press release \\
\hline & gmw.cn (06-07) & media reports & 2 press release \\
\hline & huaianmh.com (08-10) & media reports & 3 press release \\
\hline \multirow{8}{*}{ Interview (I) } & People who settle in Huai'an (01) & Interview script & $115 \min$ \\
\hline & Local citizens (02) & Interview script & $85 \mathrm{~min}$ \\
\hline & Settle after working in Huai'an (03) & Interview script & $50 \mathrm{~min}$ \\
\hline & Local citizens (04) & Interview script & $35 \mathrm{~min}$ \\
\hline & Merchants around Qing Yan Yuan (05) & Interview script & $30 \mathrm{~min}$ \\
\hline & Merchants around Qing Yan Yuan (06) & Interview script & $40 \mathrm{~min}$ \\
\hline & Tourists in Qing Yan Yuan (07) & Interview script & $25 \mathrm{~min}$ \\
\hline & Tourists in Qing Yan Yuan (08) & Interview script & $20 \mathrm{~min}$ \\
\hline
\end{tabular}

\subsection{Reliability Analysis of Data}

The reliability analysis of data used interactive reliability proposed by Kirk and Miller (1986), which means different researchers use the same method to explore the research phenomenon at the same time [81]. This article selected three researchers with similar professional backgrounds to analyze the same manuscript and observe whether the analysis results were consistent. The reliability calculation formula shown in Figure 4 can be calculated by multiplying the number of researchers with open decoding between researchers, while dividing by the sum of the open coding of the researchers (Figure 4). The coefficient is a credible value, however, if it is lower than 0.6 , its internal consistency reliability is considered to be insufficient, and the researchers need to again discuss the 
choice of a common code until it exceeds 0.6 to achieve consistency. The three researchers in this study had similar backgrounds and conducted reliability analyses three times. The common code exceeded the value of 0.6 on the third attempt, thereby improving the reliability of the research data (Table 2).

The same open coding among researchers * Number of researchers The sum of open coding among researchers

Figure 4. Reliability Calculation Formula.

Table 2. Summary of Data Sources.

\begin{tabular}{cccc}
\hline Researcher & First Reliability Calculation & Second Reliability Calculation & Third Reliability Calculation \\
\hline Doctor of Yunke Design $(\mathrm{Z})$ & 0.441 & 0.622 & 0.720 \\
\hline College design professional teachers $(\mathrm{W})$ & 0.319 & 0.543 & 0.603 \\
\hline Doctor of Yunke Design $(\mathrm{C})$ & 0.296 & 0.483 & 0.612 \\
\hline
\end{tabular}

\subsection{Data Analysis}

The background of interviewees in the research are all related to Huai'an, whether professionals who published public content or local citizens and settlers. Thus, the interviewees are collectively referred to as Huai'an public in this article. Based on the various texts, manuscripts, and verbatim drafts, a five-stage data analysis was carried out.

1. First, classify the collected data into five categories: CNKI, tourism introduction, tourism evaluation, news report, and interviews Then, proceed with interpretation and induction. Among these data, CNKI materials were coded with the letter "J" for journal, travel introductions were coded with the letter " $\mathrm{T}$ ", travel evaluations were coded with the letter " $\mathrm{E}$ " for evaluation, news reports were coded with the letter " $\mathrm{N}$ ", and interview data were coded with the letter "I". For example, J06-03 represents the third piece of data in Chapter 6 of CNKI.

2. Second, filter out the landscape narrative materials about Qing Yan Yuan and distinguish the description. For example, Riessman (1993) believes that whether the explanation is trustworthy is the evaluation standard of narrative analysis, and this standard includes persuasiveness, whether the response can be accepted, a mutual echo of international or local issues, and practicality adopted by a community that has become a way of thinking and solving problems [44]. According to this strategy, the analysis selects the reliable landscape narrative vocabulary to establish an open interpretation.

3. The filtered data is classified again, with similar meanings grouped to form subcategories as conceptual labels [82]. As an example of the operation: the 7th sentence in the verbatim manuscript of an interview with a local citizen (I02) is: "the Canal Governor-General needed to live and work enjoyably. Wouldn't you be more enjoyable and live happily and work well?" The code of this data is I02-07; "I" represents the interview data, 02 represents the second interviewee, 07 represents the 7 sentences spoken by the interviewee. The sentences of this data describe a phenomenon that can be summarized as an open decoding: the Canal Governor-General built a garden to ensure the office environment (F1-I02-07). Then, similar content as "Canal GovernorGeneral Back Garden" (F1) is grouped together into a level to form a secondary structure while the main axis concept is finally represented by the F of "functional landscape narrative".

4. Then, the topic classification of the research is concluded, and the conceptual labels after sorting are reviewed. Then, the operations of the third stage are repeated according to the purpose of the narrative research [82]. For example, for the first category of themes: Huai'an is located at the key position of Beijing-Hangzhou Canal 
(O1); Historical Water Control Center (O2); Canal Governor-General Designer (O3); the historical evolution of Qing Yan Yuan (O4). The second category theme: Canal Governor-General Back Garden (F1); Official status representative (F2); Temporary dwelling place of an emperor (F3); Stone tablets show the achievements of officials (F4); Landscape appellation expresses Canal Governor-General's mood (F5). The third category: symbol of local culture (S1); water control history display (S2), Citizen Learning Park (S3). From the above four steps, we determined the landscape narrative strategy of Qing Yan Yuan for cultural heritage sustainability, as used by individuals and groups.

5. Finally, three strategies of landscape narrative forms were summarized, namely: original landscape narrative, functional landscape narrative, and meaningful landscape narrative. The origin is represented by the initial letter " $\mathrm{O}$ ", the function is represented by the initial letter " $\mathrm{F}$ ", and the significance is represented by the initial letter " $\mathrm{S}$ "; for example, F1-N06-04 indicates that 04 items of news materials in No. 06 indicates the functional landscape narrative (F1) (Table 3).

Table 3. Code Analysis Table.

\begin{tabular}{|c|c|c|}
\hline Axial Coding & Secondary Coding Construction & Open Coding \\
\hline \multirow{13}{*}{$\begin{array}{l}\text { Origin } \\
\text { Landscape } \\
\text { Narrative }\end{array}$} & \multirow{3}{*}{$\begin{array}{l}\text { Huai'an is located at the key position of } \\
\text { Beijing-Hangzhou Canal (O1) }\end{array}$} & The transfer station of the Beijing-Hangzhou Canal \\
\hline & & Multiple canals and water systems intersect in Huai'an \\
\hline & & Government set up an agency to protect the canal \\
\hline & \multirow{3}{*}{ Historical water control center $(\mathrm{O} 2)$} & River floods occurred frequently in history \\
\hline & & Key areas for flood control \\
\hline & & Water control technology research and development \\
\hline & \multirow{4}{*}{ Canal Governor-General Designer (O3) } & Fu Jin expanded the Yamen to Garden \\
\hline & & Bin Gao built the emperor's temporary palace \\
\hline & & Qing Lin repaired the garden \\
\hline & & Other officials repaired to the environment \\
\hline & \multirow{3}{*}{$\begin{array}{l}\text { The historical evolution of Qing Yan } \\
\text { Yuan (O4) }\end{array}$} & Canal Grain Management Center \\
\hline & & Flood management and canal management \\
\hline & & Local Government Office \\
\hline \multirow{15}{*}{$\begin{array}{c}\text { Functional } \\
\text { Landscape } \\
\text { Narrative }\end{array}$} & \multirow{3}{*}{ Canal Governor-General Back Garden (F1) } & Place for Canal Governor-General officer to work \\
\hline & & Officials enjoy leisure time in the garden \\
\hline & & Officials feasted their colleagues and friends \\
\hline & \multirow{3}{*}{ Official status representative (F2) } & The landscape layout of the garden is symmetrical axis \\
\hline & & There are rich kinds of rocks in the garden \\
\hline & & The area of garden is larger \\
\hline & \multirow{2}{*}{$\begin{array}{l}\text { Temporary dwelling place of an } \\
\text { emperor (F3) }\end{array}$} & The residence of Emperor Qianlong on his tour \\
\hline & & A place for emperor to rest when inspected the canal \\
\hline & \multirow{4}{*}{$\begin{array}{c}\text { Stone tablets show the achievements of } \\
\text { officials (F4) }\end{array}$} & Emperor Kangxi praised the officials \\
\hline & & Emperor Qianlong rewarded the Canal Governor-General's achievements \\
\hline & & Other emperors messaged to the Officials \\
\hline & & Stone tablets record the events of water control \\
\hline & \multirow{3}{*}{$\begin{array}{l}\text { Landscape appellation expresses Canal } \\
\text { Governor-General's mood (F5) }\end{array}$} & Names of the garden wish no flood \\
\hline & & Names of the couplet contain canal information \\
\hline & & Names of the building implies the owner's ideal \\
\hline
\end{tabular}


Table 3. Cont

\begin{tabular}{|c|c|c|}
\hline Axial Coding & Secondary Coding Construction & Open Coding \\
\hline \multirow{9}{*}{$\begin{array}{l}\text { Meaningful } \\
\text { Landscape } \\
\text { Narrative }\end{array}$} & \multirow{3}{*}{ Symbol of local culture (S1) } & About the official garden of the canal \\
\hline & & Fusion of southern and northern Chinese garden styles \\
\hline & & Classical gardens in northern Jiangsu \\
\hline & \multirow{3}{*}{ Water control history display (S2) } & Water control technology demonstration \\
\hline & & Records of water control incidents \\
\hline & & Records of official achievements \\
\hline & \multirow{3}{*}{ Citizen Learning Park (S3) } & Cultural Sightseeing place to the public \\
\hline & & Arouse people's memory of Huai'an history \\
\hline & & Show people the water transportation culture of Huai'an \\
\hline
\end{tabular}

\section{Results}

People collectively preserve the cumulative culture of their predecessors through language, which is the result of the process of understanding the objective world. Qing Yan Yuan is a rare treasure among Chinese classical gardens that shows the artistic style of gardens with unique local characteristics, and is the largest government garden of water transportation in the Ming and Qing Dynasties. It exists as a "material" form of a historical site that preserves the memory of the past in the landscape through the entity of "place" [83]. The public's subjective ideas and thoughts give different meanings to the landscape when they see the common landscape in Qing Yan Yuan. The landscape content, through "telling stories", allows discovery of the local culture and memory, and the charm of the cultural heritage and landscape. The use of language by locals to describe scenic spots indirectly affects the personal understanding, while establishing a cultural heritage value of their own. This management method that considers local public the "owners" and "users" of cultural heritage is low-cost, and is thus conducive to the sustainable development of local cultural heritage.

In this section, we separately explain the landscape narrative strategies used by the public in Huai'an. First, the Beijing-Hangzhou Canal could not flow smoothly when Qing Yan Yuan was built because of the location of Huai'an, at which the junction of Huai River, Yellow River and Canal, and the Huang-Huai River was frequently flooded and silted up. Thus, the Cao-yun Management Center in Huai'an was established to adopt the "origin landscape narrative". Secondly, the Canal Governor-General was responsible for the control of flooding and the protection of the smooth canal when Qing Yan Yuan was the highest water control institution in the Ming and Qing Dynasties, and the place performed different functions according to the situation and adopted the "functional landscape narrative". Finally, Cao-Yun Management Center was dissolved when Qing Yan Yuan became a local leisure park, and was endowed by the public with the image of a Huai'an Canal cultural carrier, which adopted the "meaningful landscape narrative". The origin landscape narrative, functional landscape narrative, and meaningful land-scape narrative of Qing Yan Yuan together constitute the connotation of heritage value by the public. More importantly, it is easy to interpret and remember in the process of public who tells these landscape narratives to others, which indirectly promotes the sustainability of local cultural heritage practices.

\subsection{Origin Landscape Narrative}

The Grand Canal culture is an important historical background of Huai'an, in which the construction of Qing Yan Yuan originates from the maintenance of the water transport system in Ming and Qing Dynasties. Huai'an is the key point of the Beijing-Hangzhou Canal, where flood control is the top priority. Since the late Ming Dynasty, the emperor appointed the Canal Governor-General to Huai'an to direct flood control, and opened the Qing Yan Yuan as the Cao-yun Management Center. In the gathered material, we 
found the landscape narrative data of the public who dealt with the construction of Qing Yan Yuan through four conceptions: (1) Huai'an is located at the key position of BeijingHangzhou Canal; (2) historical water control center; (3) Canal Governor-General Designer; and (4) the historical evolution of Qing Yan Yuan. These landscape narratives are all related to the establishment background of Qing Yan Yuan, so it is aptly named the "origin landscape narrative".

\subsubsection{Huai'an Is Located at the Key Position of Beijing-Hangzhou Canal}

The key position of Huai'an on the Beijing-Hangzhou Canal determined the Qing Yan Yuan as the Cao-yun Management Center. In Figure 5, Beijing was the starting point of the Grand Canal and Ningbo was the end point, with Huai'an located at the midpoint of the canal. Cao-yun was an economic and trade communication line in China, and it was critical to ensure the smooth flow of the Grand Canal during the Ming and Qing Dynasties. Thus, the government established a series of water transportation agencies. Qing Yan Yuan was established during this period as a river department that was mainly responsible for canal dredging, flood control, and local disaster relief. In the first year of emperor Shunzhi (1644), the Canal Governor-General was established to manage the Yellow River, canal, and other water transportation affairs, and was stationed in Jining, Shandong, with a system of officials [84]. In the 16th year of emperor Kangxi (1677), canal transport in the Huai'an section was highly important and the Canal Governor-General Fu Jin controlled the middle and lower reaches of the Yellow River, when frequent floods occurred along the Yellow River and Huai River at the same time [85]. Then, the Water Transport Management department moved from Jining, Shandong Province, to Qing Jiang Pu, Huai'an, designating Huai'an as the canal transportation center for 183 years. The main statement regarding the establishment of Qing Yan Yuan is "Huai' an is the key position of Beijing-Hangzhou Canal", which emphasizes its important location in Cao-yun during its historical changes. Huai'an is located in the middle of the Beijing-Hangzhou Canal, at the intersection of the Yellow River, Huai River, and the Canal. More importantly, the Huai'an Qing Jiang $\mathrm{Pu}$ dock is a turning point for ships in north-south and other modes of transportation; Figure 6 shows the monument of China's north-south boundary that is located in Qing Yan Yuan. Therefore, the river in Huai'an and the Grand Canal is safe throughout the waterway. For example, "Huai' an is located at the geographic boundary between North and South China, and used to be a transportation point for boating in the south and horseback riding in the north" 14); "The southern ship and northern horses then stopped where the boat landed, meaning that the ship from the South must change to horses to continue northward. The same goes for the horses from the north, which must change to the boat "(O1-N09-06). Huai'an is the midpoint of the water transportation channel, which is convenient for the implementation of river regulation policies and flood control, and beneficial to water transportation management and river governance. Thus, the public considers "the transfer station of the Beijing-Hangzhou Canal", "the confluence of several canals and water systems", and "the establishment of the water conservancy agency by the Qing government" were the reasons for the establishment of Qing Yan Yuan. As shown in Figure 7, Huai'an was located at the confluence of multiple water systems. In general, "Huai'an is located at the key position of Beijing-Hangzhou Canal "is a landscape narrative concept adopted by the public, as represented by jstour.com, qitrip.com, bytravel.cn, ourjiangsu.com, wenming.cn, bilibili.com, toutiao.com, gmw.cn, huaianmh.com, and cnki.net. Examples are "Qing Jiang Pu is an important town on the bank of the canal, where several government offices have been located since the Ming Dynasty" (O1-J03-03); "The first Canal Governor-General Fu Jin, who was a native of Xiang-huang-qi of the Han Army, was stationed at Qing Jiang Pu under the orders of Emperor Kangxi to. He was in charge of the highest water control institution in China-Water Transport Management at the intersection of Yellow River, Huai River, and Beijing-Hangzhou Canal" (O1-N02-02). 


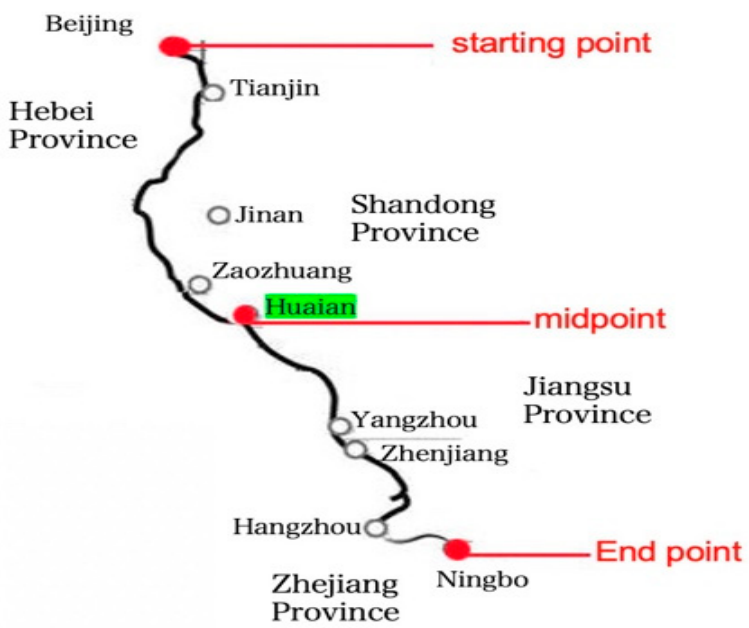

Figure 5. Beijing-Hangzhou Canal.

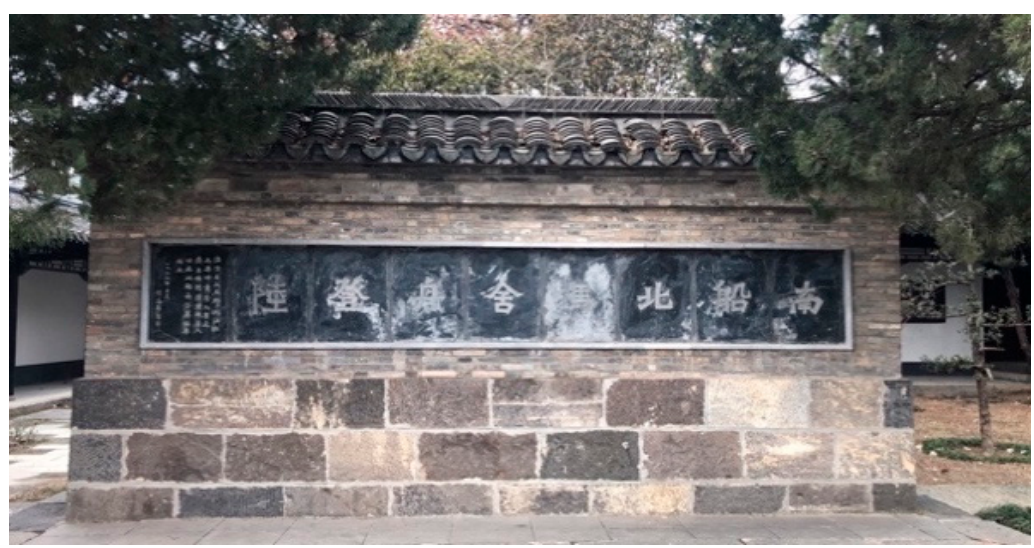

Figure 6. The North and South Boundary Marks.

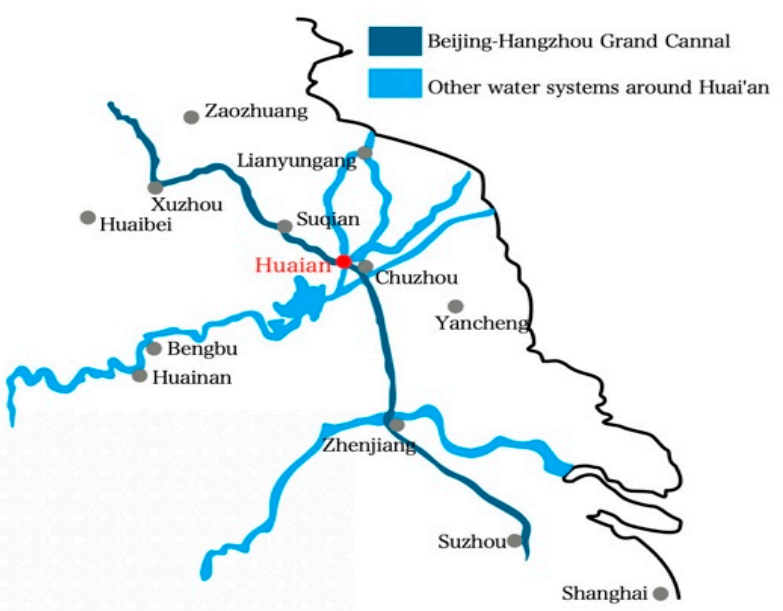

Figure 7. Water System around Huai'an.

\subsubsection{Historical Water Control Center}

Qing Yan Yuan was the location of the water transport management institution and flood control department during the Ming and Qing Dynasties. According to historical records, floods frequently occurred in the Yellow and Huai Rivers, which caused the destruction of waterways and the inundation of farmland, causing misery for local people's in the late Ming and early Qing Dynasties. During the Wanli year of the Ming Dynasty, 
Yunxi Lake expanded rapidly and "the lake water rose every spring and summer, flooded farmer's fields” 「每春夏湖水涨, 没民田」 [86]. As recorded in Sizhou Chronicles by Kangxi year, 1258 hectares and $45 \mathrm{mu}$ land were destroyed, and 1117 hectares and $91 \mathrm{mu}$ were permanently submerged in Sizhou at that time [85]. In addition, the Great Dyke of Hongze Lake in Huai'an broke more than 140 times from 1575 to 1855 [87]. Therefore, the Cao-yun Management mechanism in Huai'an became the canal management center responsible for construction for water conservancy. More well-known is Jixun Pan, which adopted the strategy of "all water from the Huai River flows into Hongze Lake to raise the water level to resist the Yellow River" 「蓄清刷」 and “Build dikes to prevent the Yellow River from invading the south" 「束水攻沙」 in the Wanli year of the Ming Dynasty. In the Qing Dynasty, Canal Governor-General Fu Jin and Penghe Zhang raised the levee of Hongze Lake and widened lakes to guide river water. Bin Gao set up five wooden keels on the south bank of the Yellow River to force it to flow to the north bank. Shixu Li used the technique of diverting the flood to build the dyke「分洪治水」, and retained dikes by filling straw and reed with earth 「厢埽」, which ensured the canal was smooth [75]. In addition, there were five dams in Huai'an, the name of them are benevolence, righteousness, rituals, wisdom, credibility, which provide proof of the Canal Governor-General's flood controls. These materials together constitute the "historical water control center" of Qing Yan Yuan in the mind of the public. For example, "Qing Yan Yuan is the site of the ancient government office for water control with the highest rank, the longest duration and the most officials in Huai' an history" (O2-N13-01); "In the early Qing Dynasty, although Qing Jiang Pu is the most important place for river control projects at the confluence of the Yellow River, the Huai River and the Beijing-Hangzhou Canal, the General River Administration is located at Jining in Shandong Province, which is far away and inconvenient. In order to grasp the water situation and direct the river nearby, the Qing Dynasty government set up official posts to deal with floods at Qing Jiang $P u$ " (O2-N04-02); "Qing Yan Yuan is a scenic spot in the downtown area of Huai'an. At that time, it was set up by the government to deal with flooding along the Yellow River and Huai River, while now it is a key cultural relic site under national protection" (O2-E02-22).

\subsubsection{Canal Governor-General Designer}

Qing Yan Yuan was the site designated for the Canal Governor-General to work and live. The garden was specifically assigned by the Ming and Qing governments, who were also responsible for its upkeep. The canal management agency employed 72 positions and 58 river officials in the 183-year period [88], which were responsible, to different degrees, for the restoration, reconstruction, and expansion that were mainly performed by the Canal Governor-General during this period. In the seventeenth year of Kangxi (1678), $\mathrm{Fu}$ Jin was the first Canal Governor-General who "dug ponds and planted trees to build office and living spaces", and established branches on the basis of household registration management [86]. Later, in the thirty-ninth year of Kangxi (1700), Penghe Zhang, a famous Canal Governor-General, opened a pool [85]. From the 8th year (1731) to the 11th year of Yongzheng (1733), Qidao Gao and Zengyun Ji wrote to the emperor outlining how to improve the office environment by "modifying the flow direction of water" [84], and Bin Gao further developed the garden in the 15th year of Qianlong (1750) [89]. In the 30th year of Qianlong (1765), Hongjian Li built the "Hefeng Pavilion", which is now the Zhan Pavilion [90]. The main construction of the garden was completed by Qing Lin in the 13th year of Daoguang (1833), which was recorded in the in a painting book called Hongxue Karma: "At that time, the level of the river was quiet, and the work was idle ... Qing Yan Yuan was repaired by pavilions, bridges, long corridors, and halls" [91]. Finally, the Canal Governor-General office was abolished, and the Cao-yun Governor-General took control and moved to the garden in the 10th year of Xianfeng (1860). It was during this time that Kuilong Chen built the "Wisteria Flower Garden" when he saw an old tree vine [92]. The garden formed a unique classical official garden due to the construction of the Canal Governor-General and Cao-yun Governor-General (Figure 8). Therefore, the establishment of Qing Yan Yuan is attributed to the "Canal Governor-General Designer". For example, 
the public's landscape narrative content shows, "Qing Yan Yuan was a private garden firstly built by Fu Jin who was the Canal Governor-General" (O4-N08-02); "Qing Yan Yuan formed its full scale after every Canal Governor-General's renovations" (O4-J06-03); "The most famous is the He fang Academy which Bin Gao built for his son-in-law who was the emperor" (O4-I01-13); "There was a Canal Governor-General named Qing Lin who liked to design gardens, built a lot of pavilions, even the number reached 16" (O4-I02-13).

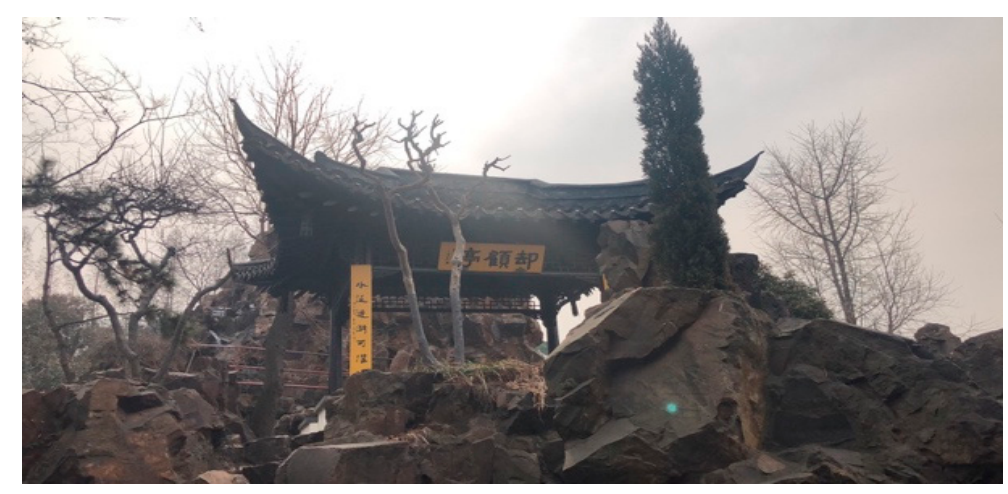

Figure 8. Rockery and Pavilion.

\subsubsection{The Historical Evolution of Qing Yan Yuan}

Qing Yan Yuan has experienced multiple identity changes, and each transformation occurred during the Ming and Qing Dynasties. The earliest identity of Qing Yan Yuan was the household registration management department. By order of $\mathrm{Fu}$ Jin, to direct flooding near Qing-jiang River in Huai'an, the garden temporarily became the water control office in the 17th year of Kangxi (1678). Later, Qing Yan Yuan had the status of canal management organization because Qing-kou was an important area to canal management, and the temporary office was changed to the office of the Canal Governor-General (Figure 8). At the end of the Qing Dynasty, in 1860, the government abolished the Water Transport Management department and the Cao-yun Management department moved to the garden to became both the office of the river course and grain transport. Transportation on the Grand Canal declined and maritime transportation was developed during this period. The railway also became a more economical means of transportation, and the administrative status of the Cao-yun Management department began to weaken. Finally, the water transportation management posts were disbanded and Qing Yan Yuan successively became the office space of commander-in-chief of Jiangbei Province, Jiangbei Governor's Mansion, Jiangbei Military Region, Huaiyang Government Office and Local Government. Then, Beijing-Hangzhou Canal was no longer in use because of the Yellow River changed the direction in the 30th year of Emperor Guangxu (1904) [77]. In general, Qing Yan Yuan was a community park opened to citizens who recognized its multiple identities via the spread of anecdotes and the indicative landscape elements when the Qing Dynasty ended. For example, "the former household management department was turned into the yamen of the flood control agency" (O3-E03-04); "We saw two signs containing the Jiangnan River management agency and the Cao-yun Governor-General Transportation Department that were hung to represent them" (O3-N07-05); "it was burned down during the peasant uprising movement in the late Qing Dynasty, and ministers rebuilt it consistent with its original appearance while the Water Transport Management was abandoned to became a park " (O3-I03-09).

\subsection{Functional Landscape Narrative}

Qing Yan Yuan became a well-known site of Huai'an because the Water Transport Management Agency once played an important role. The Canal Governor-General who lived in the Qing Yan Yuan left traces, such as handling the water transportation and flood affairs, and receptions for the patrol of the emperor. For example, although the construction scale of the garden should suit the status of officials, some buildings are 
beyond the hierarchy because they were used as palaces for the emperor. In addition, there are a large number of stone tablets in the garden that contain encouragement, praise, and other content written by the emperor of the Qing Dynasty. In general, Qing Yan Yuan has multiple functions, such as an office and leisure place for the Canal GovernorGeneral. These functions provide the materials that allow the public to organize landscape narratives to establish the notions of cultural heritage: (1) Canal Governor-General Back Garden; (2) official status representative; (3) temporary dwelling place of an emperor; (4) stone tablets show the achievements of officials; (5) landscape appellation expresses Canal Governor-General's mood. As these vocabularies are all related to various functional features of Qing Yan Yuan, they can be referred to as the "functional landscape narrative".

\subsubsection{Canal Governor-General Back Garden}

The Canal Governor-General had an important responsibility to remediate blocked rivers and formulate the water control strategy, and the Qing Yan Yuan (also known as the West Garden) became the best place to relieve pressure and relax (Figure 9). Historical records show that the Canal Governor-General entertained relatives, friends, and colleagues. For example, ZengJun Ji, who was the Jiang Nan Canal Governor-General, invited friends to a party in the garden to enjoy the cool air when he was stationed at Qing Jiang $\mathrm{Pu}$ in the Yongzheng 8th year (1730). The poem "West Garden" notes that: "The wind was quiet and the clouds were idle, while flowers and pavilions reflect each other. Even though the scent of lotus rushed over the face, it can't smell the scent of tea. A few orioles crowing in the forest, and the white crane screamed that means it was noon. Relaxing work when the canal was not flooded, then have a party with friends in the garden. However, the fact was bleaker garden courtyard was deserted, which sitting there I don't know what to say, only write poetry to express my feelings" [93]. In addition, the Canal Governor-General Jishan Yin invited Mei Yuan, a famous scholar, as a guest to the garden in the 18th year of Emperor Qianlong (1753). Mei Yuan wrote a poem as a gift to say goodbye: "There were some people playing together that occasionally stopped by the lotus garden. The old attic was thought to be a new and the clear pond was like a pool" [90]. The Canal Governor-General Qing Lin invited friends and family to participate in garden activities from the 13th (1833) to the 22nd year (1842) of Daoguang, as recorded in the "Appointing Snow in the West Garden" of the Hongxue Karma: "The guests came to have fun when the work was over, so set up banquets. And the lifestyle was having a party with relatives and friends on holidays in the garden, and planting flowers and trees, fishing, raising white cranes, or inviting the moon and wind to gather together was really wonderful fun" [91]. Then, Junzai Huang, who was a Huai'an's scholar during the year of Emperor Tongzhi, wrote notes in Jinhuxun Ink: "It was a past story that the Canal Governor-General's garden was the most luxurious in Qing Jiang Pu, where Gongyou Zhang and his friends were drinking and playing here when they inspected the canal“ [92]. From the above we know that the landscape of Qing Yan Yuan is rich and was a place for Canal Governor-Generals to enjoy the beautiful scenery and entertain colleagues, relatives, and friends (Figure 10). For example, the landscape narrative of "Canal Governor-General Back Garden" includes: "The West Garden is the Canal Governor-General's Office" (F1-N12-02). "Qing Yan Yuan is a classical garden that was originally the back garden of the Governor-General's Court" (F1-T08-01); "Qing Yan Yuan was both the yamen and garden of Ming and Qing river officials" (F1-J03-06); "Poems described the landscape and the life in the garden of Canal Governor-Generals and scholars when the Canal Governor-General's work was finished" (F1-J01-08); "During the periods when the Canal Governor-General and Cao-yun Governor-General were stationed here, the West Garden was used as a place of recreation" (F1-J01-04). 


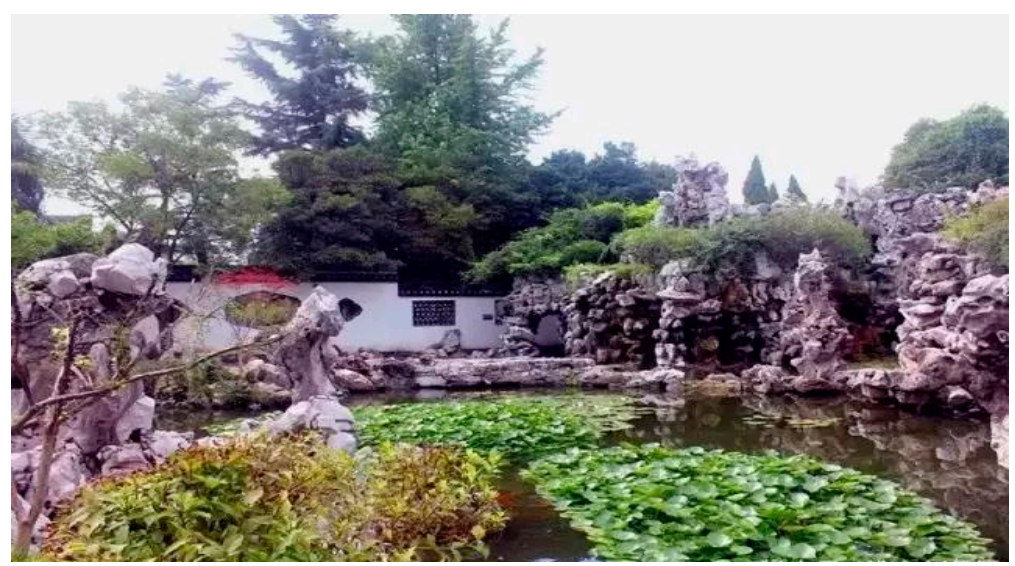

Figure 9. Southern-Style Rockery.



Figure 10. Northern-Style Rockery.

\subsubsection{Official Status Representative}

The construction regulation of Qing Yan Yuan should be in line with the official status, which is specified by a local government institution. That is, the owners of Qing Yan Yuan were the Canal Governor-Generals who were conferred the positions of "deputy secretary of defense" and "assistant to the Supreme Supervisory Organ", which were "Zheng II Pin" or "Zhengyi Yi Pin Senior Officer", also known as "Hetai", "Heshuai", and "River Superintendent" $[75,94,95]$. The construction of buildings and gardens is symbol of status in the "ritual system" of Chinese feudal society, and also has an aesthetic effect [96-98]. However, the Governor-General had a higher status in the Qing Dynasty, and the Qing Yan Yuan, as a government building, was second only to the emperor's palace. Thus, the construction scale of Qing Yan Yuan reflects the "official status representative". For example, the layout of Qing Yan Yuan follows the order of the traditional building concept, in which the office buildings of the Canal Governor-General and the main places of the garden were distributed on the central axis. As shown in Figure 11, the front of main buildings faces south and the back faces north, thus forming a central axis, such as Liu Ping Pavilion, Hewang Pavilion, Huaixiang Hall, Zhan Pavilion, and He fang Academy, which are distributed in sequence from south to north. XuYuan, the Jiangnan Canal GovernorGeneral's office, Yu-bei Yuan, and Huanyi Villa lie to the east, and to the west are located the Wisteria Garden, YeYuan, and Ming Dynasty Guandi Temple [75,99]. However, the construction system of the Qing Yan Yuan neither transcends the official status nor is equivalent to that of an ordinary garden. Thus, it is between the royal garden and a private garden, and some interpretations of mountains and stones are related to this: "The rockery and stones that in the garden, which were transported by canal and then built, only officials are treated like this" (F2-E03-07); "The area of the pond is almost half size of the garden in Qing Yan Yuan that is linked to the identity of the owner" (F2-E03-08); "The architectural style in the garden 
that creating a serious atmosphere such as the calm, heavy, and orderly"(F2-J03-09); "Qing Yan Yuan is an official garden which uses the precious materials that have two different styles of rockery" (F2-N06-02).

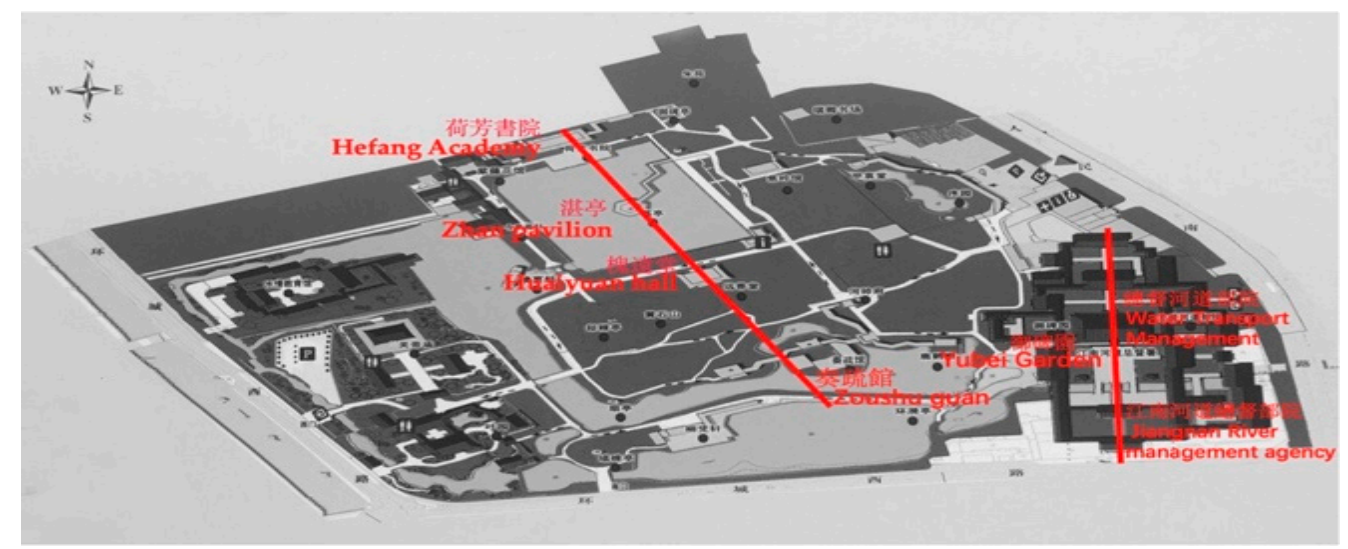

Figure 11. Layout of Qing Yan Yuan.

\subsubsection{Temporary Dwelling Place of an Emperor}

Although Qing Yan Yuan was mainly designated as a place for the Canal GovernorGeneral to work and live in, the emperor also visited it. It is one of the few places where the emperor stayed in addition to the Forbidden City in Beijing, and is called the Xing-gong. "Cihai" interpreted "Xing-gong" 「行宮」 as "a palace outside the ancient capital where the emperor lived when traveling." Thus, Xing-gong is a temporary place to stay and rest at important locations to meet the needs of ancient Chinese emperors when on parade, hunting, and military activities [100-102]. One function of the Qing Yan Yuan was as a Xing-gong; because of its convenience, two emperors of Kangxi and Qianlong of the Qing Dynasty lived in Qing Yan Yuan to inspect the construction of the Grand Canal when they went to the Jiangnan area [103-105]. For example, Qianlong once said that "Qing-kou is the junction of Huang and Huai Rivers, which is the first important area for flood control in Jiangnan" [106]. In Volume 4 of the "Southern patrol record" of "Canal engineering management", it was recorded that the Canal Governor-General Bin Gao and assistant Shi Zhang invited the emperor to inspect the Cao-yun Canal while Qianlong readily agreed to go [107]. To ensure that the emperor lived more comfortably, Bin Gao chose the best position to build the "He fang Academy" as the temporary residence in Qing Yan Yuan before the first visit of Qianlong, who visited Huai' an four times in total to inspect the river course [104] (Figure 12). Zengyun Ji recorded "Bin Gao was stationed in Jiangnan Canal Governor-General's Court in the early years of Qianlong, and the He fang Academy was built in his expansion of the site and has been there for more than 200 years". In short, He fang Academy was the "temporary dwelling place of an emperor", and accommodated Qianlong's visit in 1751 and 1784 [108]. Therefore, it became a well-known fact that Qing Yan Yuan was a "Xing-gong", and the He fang Academy was the place where the emperor lived. For example: "Qing Yan Yuan has survived the changes and used to be Qianlong's residence" (F3-N06-03); "Qing Yan Yuan was the daily office and residence of the Canal Governor-General while it was also the reception place for the emperor to inspect the floods" (F3-J03-11); "In order to please the emperor, the officials specifically decorated buildings in imitation of the folk houses in Huai'an" (F3-N05-07); "when hearing the name Zou Shu Guan, we know the place was used for work for the emperor and official" (F3-E02-11); "He fang Academy was built by Bin Gao to welcome his son-in-law who was the Emperor Qianlong (F3-E03-11)"; "Kangxi, Yongzheng, and Qianlong all traveled to the south of China to inspect the Grand Canal, and they lived in Qing Yan Yuan" (F3-E02-27). 


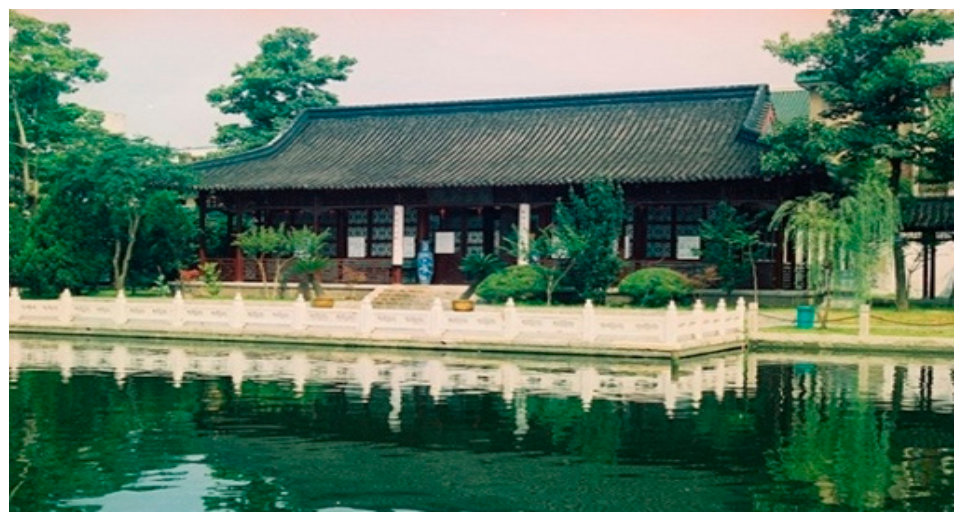

Figure 12. He fang Academy.

\subsubsection{Stone Tablets Show the Achievements of Officials}

Inscriptions on stone tablets are a commemorative and demonstrative landscape element that combine with classical gardens to explain historical and cultural connotations. We know that the stone tablet inscriptions have high historical, cultural, and artistic value, and comprise historical significance, cultural landscape, and calligraphy art research materials [109-111]. The stone tablets is the unique scenery of the garden that represent the historical stories to increase its connotations [112,113]. There are 17 stone tablets in Qing Yan Yuan, namely, one of Emperor Kangxi, 13 of Emperor Qianlong, one of Emperor Daoguang, one inscription without words, and one Chastity Stele. These are mainly the emperor's reward for the honor of the Governor-General, such as the many inscriptions on the promenade, as shown in Figure 13. The "Indifferent Tranquility" stone tablet bestowed by Emperor Kangxi is praise and affirmation of the Governor-General Penghui Zhang. In addition, Qianlong awarded inscriptions to Bin Gao, Fenghan Li, Jin Gao, and Zhongshan Bai during his six southern tours, and the contents of the inscriptions were "Flood control achievements", "Work diligently", "Message to the Governor-General", etc. In addition, the emperor of Daoguang inscribed "Governor-General of Li Shixu who met the emperor" on the stone tablets [114]. Among these rewards, the Governor-General of Penghui Zhang "raised the levee of Hongze Lake and widened lakes to guide river water", and Bin Gao used the "Qing-kou Mulong" technique [75]; the remarkable effect on the Grand Canal control was affirmed by the emperor by giving a stone tablet. Mei Yuan wrote "Four Poems say goodbye to He fang Academy" that described: "Look at the deepest reward of Emperor, steles stood against the setting sun. Most of the stone tablets in the garden were awarded by high officials" [93]. Therefore, the stele inscription symbolizes the praise given to the Canal Governor-Generals who contributed to the transportation of water, and "Stone tablets show the achievements of officials "represents the public's understanding of the existing steles in Qing Yan Yuan. Figure 14 shows the stone stele awarded to Gao Bin by Emperor Qianlong. For example: "The Imperial Stele Pavilion and the Stele Corridor have many inscriptions, most of which were rewards by the emperor of Qing Dynasty" (F4-J07-06); "The Stele Garden represents the achievements of river governance in previous generations" (F4-N06-05). "The Indifferent Tranquility stone tablet represents the award of the emperor that praises the achievement of official "(F4-N04-06); "The three-sided corridor with many stone tablets embedded in the front of corridor is the emperor's commendation to the Governor-General." (F4-E01-06); "The Yu-bei Yuan is the emperor's reward for the governance of the canal" (F4-N09-04). 


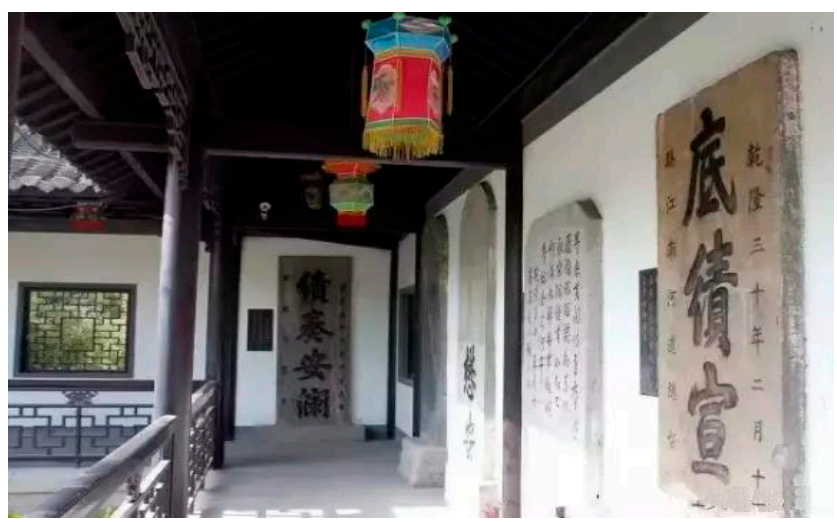

Figure 13. The Corridor of Yu-bei Yuan.

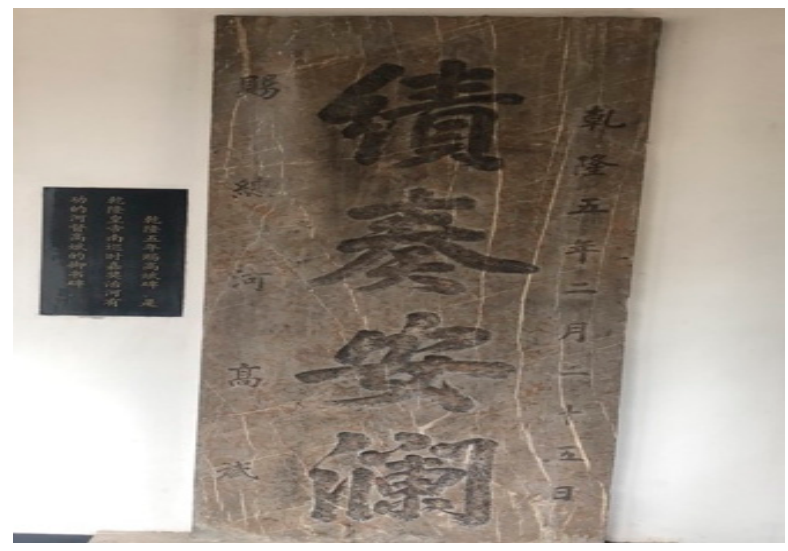

Figure 14. The Inscription Given to Bin Gao by the Emperor Qianlong.

\subsubsection{Landscape Appellation Expresses Canal Governor-General's Mood}

The naming of Chinese classical gardens is related to the main functions of the gardens, which also reflect the sentiments of the owners of the gardens. Generally, the prominent garden theme is "words concise but full of meaning" [112,115,116], and naming forms include memorial, scenery, aspiration, and lyricism. Plaques and couplets are mostly written by the garden owner according to his personal mood, which the viewer can see “「象外之象、景外之景、弦外之音」 the image outside the picture, the scene outside the garden, the sound outside the space" through his personal association [112,117]. This is mainly due to the cultural habit of ancient Chinese literati who express their personal aesthetics, ideals, and aspirations through poetry. Successive Canal Governor-Generals wrote poems and couplets on plaques and buildings to encourage themselves and declare their aspirations when they presided over the management of the Grand Canal in Qing Yan Yuan. The name of Qing Yan Yuan changed in different periods due to this reason; for example, the initial name of Qing Yan Yuan was "HuaiYuan" because Huai'an is located at the intersection of the Huai River and the canal, where most local buildings were named "Huaiwu" [90]. Then, the Canal Governor-General of Jing Wu changed the name to Dan Yuan, according to the "Indifferent Tranquility "stone tablet, for self-encouragement during the Jiaqing period. It was later renamed "Qing Yan Yuan" which was derived from the meaning of "The river was calm and grain was plentiful while the people lived and worked in peace and contentment「河清海晏, 五穀豐登, 百姓安居」”[84]. In addition to the name of the garden, the other designation also expressed the Canal Governor-General's description of the Grand Canal as smooth and calm. For example, a poem was written about the "He fang Academy" that expressed the meaning of plaque as "Hide bad revelation and show the good to take the homophony of river defense" [89], which implies flood prevention and management. Qing Lin once renamed the Hengjian hall to the "Lan Tian 
Feng Ding pavilion" and the "Tian Bo Lou" was set up during the Tongzhi period, in the hope that the river course in the Huang-Huai area would "Calm without flood". As shown in the landscape narrative data: "The plaque in the garden has the meaning of water control and the ideals of the Canal Governor-General" (F5-N12-10); "Qing Yan Yuan was not the original name, which we named in the hope that Huai river was calm and had no floods"(F4-I04-06); "Qing Yan Yuan implies the water was calm without flood" (F5-N07-02); "the buildings in the garden were all named in line with the theme of 'water governance', such as the boat-form pavilion of Qingyan Fang and Jinyu Tower "(F5-T10-05)"; the name of Jinyu Tower is taken from Du Fu's poem of "Lin Yu Si Xian that implied a virtuous scholar with heavy rain after a drought" (F5-N09-05).

\subsection{Meaningful Landscape Narrative}

Although the function of Qing Yan Yuan's water transportation management organization has disappeared, its historical background has special significance because it became a symbol of Huai'an culture in the public's consciousness. The public links the historical site to water transportation through landscape elements, such as monuments, rockery, lake rocks, buildings, and courtyards when Qing Yan Yuan was an open leisure area and sightseeing location, to convey the information of the Grand Canal. The specific landscape description language is: (1) symbol of local culture; (2) water control history display; and (3) citizen's learning garden. This vocabulary content establishes the meaning recognition system of Qing Yan Yuan, that is, "meaningful landscape description".

\subsubsection{Symbol of Local Culture}

The garden style of Qing Yan Yuan is unique because it was created with rich cultural connotations, and it was the former government office for river management and the highest water transport management institution in Chinese history. The public has given many titles to Qing Yan Yuan such as: Official Garden of Water Transport, First Garden of Jianghuai, Subei Garden, and Classical Garden of Huai'an. The Cao-yun Governor-General Department is the "predecessor" to the Qing Yan Yuan, which is known as a place of residence and for use by the Canal Governor-General officials. Some descriptions are provided in the landscape narrative, such as "Qing Yan Yuan is the only well-preserved classical garden in Huai'an, and also the preserved official garden in the history of Chinese water transport" (S1-T01-03)". Qing Yan Yuan is called the "First Garden of Jianghuai" and "Subei Garden" because Huai' an is located in the Changjiang River and Huai River valleys, which are located in northern Jiangsu. In addition, the construction style of Qing Yan Yuan is different from that of the northern royal gardens and private gardens, and is a combination of southern and northern characteristics. For example, the rockery using Taihu Lake stone is located at the entrance of garden and the material came from the south of China, whereas the rockery in the middle area is Yellowstone, and the material came from the north. In addition, the plants include tall deciduous trees of the north and small evergreen trees of the south, and both are integrated into the garden. Our investigation showed that this is because Huai'an is located at the geographic boundary between the North and South of China. Furthermore, the water transport channel further promotes the exchange of materials between different regions. These characteristics with historical and cultural connotations make Qing Yan Yuan a classical park that distinguishes itself from the modern gardens around Huai'an. In summary, the Huai'an public recognizes the diverse connotations of the garden, regardless of the names of the Official Garden of Water Transport, First Garden of Jianghuai, Subei Garden, or the classical garden of Huai'an, which are based on the history of the water transport management institution. For example: "The scenic spots in the Qing Yan Yuan are all related to the water transport culture" (S1-E02-19); "It is a government garden related to water control and the person in Huai' an who thought of it as the first garden of Jianghuai River" (S1-N02)-01)); "The plants in the Qing Yan Yuan have both the beauty of the south and the majesty of the north that are typical of the classical gardens in northern Jiangsu" (S1-T09-02); "The public in Huai' an called it 'first garden of northern Jiangsu' 
and it is unique because it represents the unity of Beijing's imperial gardens and private gardens while it located in southern Jiangsu"(S1-E03-10).

\subsubsection{Water Control History Display}

Qing Yan Yuan was an important historical site at which many officials during the Ming and Qing Dynasties oversaw the remediation of the local water system and made great contributions to ensure the smooth flow of the Grand Canal. The calm of the Yellow and Huai Rivers, and the entire Beijing-Hangzhou Canal channel, were the responsibility of the Canal Governor-General, who studied water control methods, aimed to control flooding, and maintained the passage of the Grand Canal. In addition, water control strategies, flood disaster records, and construction of water conservancy facilities have spread until today to become an important cultural symbol of water management. For example, "Strategic Strategy for River Control" by Fu Jin, "Suggestions for River Protection" by Zengyun Ji, "An Lan Minutes" by Duan Xu, "River management record" by Penghe Zhang, and "Tool Atlas of Canal Project Management" by Qing Lin [118] are not only important reference books for water control in ancient China, but also represent the precious cultural heritage of water transportation. In addition to the Classic books of water control, the inscriptions in the park also reflect important history. These evidence that the Canal Governor-General Wu Tang rebuilt the Qing Yan Yuan in the late Qing Dynasty and placed the stone tablets awarded by emperors in different periods that symbolize the achievements of their work in the stele corridor, thus forming today's stele display gallery. Historical scene restorations were also added to Qing Yan Yuan, such as the simulation of the Canal Governor-General's office (Figure 15), the Kangxi inspection of the Qing-kou River Engineering, and the flow diagram in different periods of the Huang River, Huai River and the Grand Canal. In addition, the construction location of the reduction dam, including the sluices and river banks, also form part of the "water control history display" of Qing Yan Yuan, which showcases the contribution of water transportation to the history of Huai'an. As shown in the narrative materials: "Qing Yan Yuan shows the best of Huai'an, along with the rise and fall of the canal when there were many famous ministers and Canal Governor-Generals" (S2-I06-09); "Huai'an still has many water transport sites such as the five dams of Ren, Yi, Li, Zhi, Xin, others contain the Qing-kou lock and ship locks in Chuzhou, all these were built by those Canal GovernorGenerals" (S2-I04-15); "Huai'an was originally a canal-related city that was brilliant but fell away late, but Qing Yan Yuan can be regarded as a microcosm of those years"(S2-E03-11).

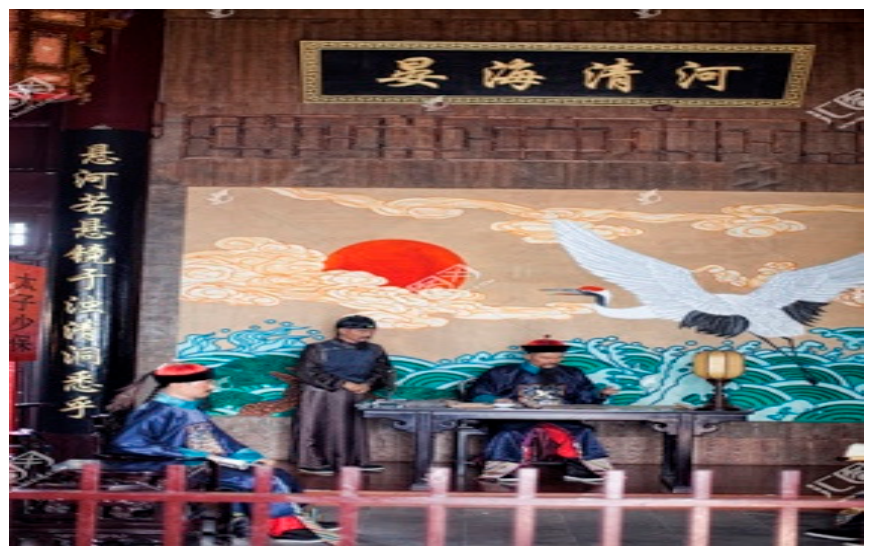

Figure 15. Office Simulation of the Canal Governor-General.

\subsubsection{Citizen Learning Park}

Qing Yan Yuan contains important landscape architecture for the public to learn about Huai'an culture, and contains the historical background of water transportation in the Ming and Qing Dynasties (Figure 16). It is the only government garden in the history of water transport [108,119], and contains rich artistic and historical values. As such, it is the most representative classical garden in Huai'an. In addition, it is free to enter for the public 
and has become the most popular and frequently visited garden. In the garden, visitors admire the beautiful scenery or have informal parties to gradually understand its historical background. Thus, it is the optimum learning environment for local cultural heritage. For example, the distinctive styles of southern and northern rockery both exist in the garden, and the building names imply the meaning of river governance. The inscriptions symbolize the achievements of the Canal Governor-General and the couplet poems reflect the mood of the master. All of these elements provide learning material to the public. Therefore, it has become a local "citizen learning park"(Figure 17), as expressed in: "Water transport culture was the most glorious time in Huai' an while Qing Yan Yuan now is a medium for the people of Huai'an to feel those years" (S3-I03-05); "It was the yamen of water control department specially built by the imperial court, today it has become a place for people to relax and exercise" (S3-N04-08); "The antique atmosphere of Qing Yan Yuan is a bit like the architecture of Jiangnan gardens that also has a strong sense of history" (S3-04-12); "It's often lively in Qing Yan Yuan, where Huai'an people like to come, such as children have picnics, high school students learn local history lessons, and the elderly have a party" (S3-I08-02).

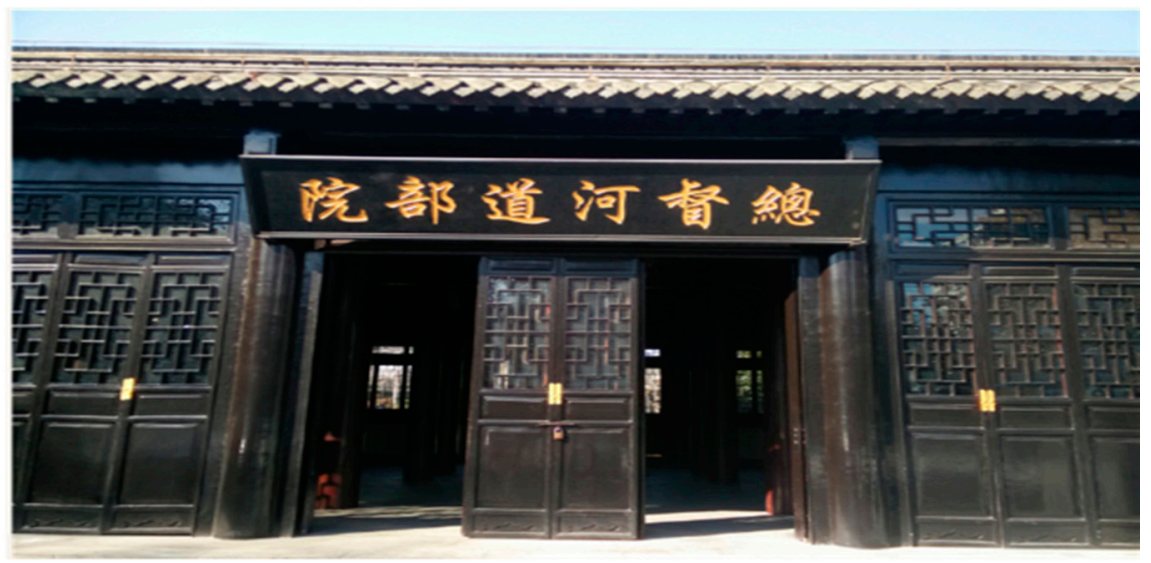

Figure 16. Water Transport Management Agency.

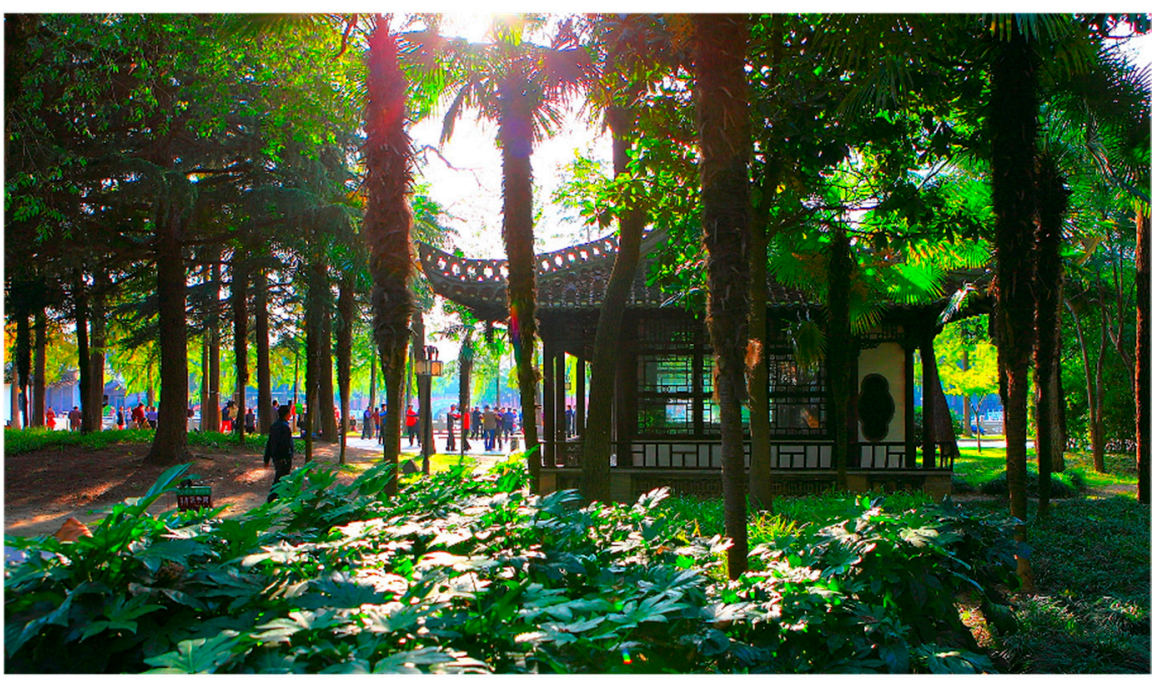

Figure 17. The local public in the Garden.

\section{Discussion}

This paper contains many interviews with residents with non-professional backgrounds, in addition to the writers of scholarly journals, official reports, and other related content, which were then summarized, coded, and decoded. These landscape narrative materials are significant expressions that provide an understanding of the interpretation of 
local cultural heritage. The language narrative of the landscape theme allows the public to become the disseminators of heritage values, and leaves the local culture and spirit to the future generations. It also conforms to the sustainable cultural heritage management model $[28,29]$. From the address of Qing Yan Yuan in Huai'an, the public realized its special position as the key to flood control in the Beijing-Hangzhou Canal. In addition, the buildings in different periods indicate that successive officials have repaired the environment of Qing Yan Yuan, and the later expansion of Ye Ting Memorial Garden shows that the function of it changed due to historical changes. Overall, the landscape of Qing Yan Yuan is vast and integrates landscapes, flowers, trees, lakes and stones, inscriptions, and pavilions. Historically, it served as the office and living place of local officials during the Ming and Qing Dynasties, which indirectly reflected the social status of Canal Governor-Generals. These significant functions of Qing Yan Yuan also enhanced the symbolism of the canal culture in the space. Therefore, the public gradually recognized the Huai'an canal culture due to its construction, site selection, and the style of architecture and rocks in Qing Yan Yuan. Furthermore, the Water Transport Culture Museum in the garden helped the public realize the value of cultural heritage for present and future generations.

In summary, we observed that the Huai'an public, with a mix of professional and nonprofessional backgrounds, organized their personal notions according to three aspects—origin, function, and meaning-which established a basic understanding of the historical relic of Qing Yan Yuan through landscape narrative materials. Behind these value concepts is the comprehension by the Huai'an public of cultural heritage sustainability as "Past presentation, place identification, and future education." More importantly, these heritage values are inherited by the local community through the oral interpretation of landscape, so that the sustainability of local cultural heritage can be practiced accordingly.

\subsection{The "Past Presentation" between the Original Landscape Narrative and Cultural Heritage Sustainability}

The original landscape narrative is the public's understanding of the background of the construction and establishment of Qing Yan Yuan. In the process of data analysis, we discovered that the public used concepts such as "Huai'an is located at the key position of Beijing-Hangzhou Canal", "Historical water control center", "Canal Governor-General Designer", "The historical evolution of Qing Yan Yuan", which formed the basis of the public's awareness of why the Grand Canal governance institutions were established in Huai'an in the Ming and Qing Dynasties. In addition, these expressions tell others something about the renovation and transformation of the well-known position of the Canal Governor-General, including how it evolved from the highest institution of river management to a local management department. The whole conceptual process is the sustainable implementation of cultural heritage resulting from public actions. Through the public's attention to the landscape and understanding of the scenes, it is transformed into a language narrative that forms personal landscape experience while establishing a historical framework of Qing Yan Yuan. This is the resurrection of the past of the place by the public through the interpretation of space. Therefore, the original landscape narrative formed by the public establishes the concept of "resurrecting the past" in the local cultural heritage value.

\subsection{The "Place Identity" between the Functional Landscape Narrative and Cultural Heritage Sustainability}

The functional landscape narrative is the public's understanding of the past environment usage through landscape elements and space layout planning. In terms of spatial layout, Qing Yan Yuan covers an area of about 8 hectares, of which one half is the location of an office building and the other half is a space for leisure. Although Qing Yan Yuan now has an open space that encourages citizens to visit and enjoy the garden, the public still clearly knows that the Water Transport Management Agency had an important historical function during the Ming and Qing Dynasties. Qing Yan Yuan was designed for habitation and recreation by Canal Governor-Generals, and even received emperors who came to inspect the canal in plain civilian clothes. The data shows that the contents of the landscape 
described by the public are all related to government affairs, and status, merits, ambitions, and life of the Canal Governor-Generals. The appellation of the garden, buildings, and the decorative couplets reflected the ambitions and ideals of the officials. In addition, a large number of stone tablets were the inspiration for the Canal Governor-Generals, while also showing that the emperor of the Qing Dynasty attached great importance to the smooth transportation of water. Therefore, the contents of these landscape materials, according to the public, formed the functional concepts of the place, such as "Canal Governor-General Back Garden", "official status representative", "temporary dwelling place of an emperor", "stone tablets show the achievements of officials", and "Landscape appellation expresses Canal Governor-General's mood". These concepts indicate it was a government office building and a landscape garden earmarked for officials' leisure during the Ming and Qing Dynasties, and that the public generally have a basic understanding of the site's usage. At the same time, the public gained the identity of Qing Yan Yuan through the content of the landscape narrative, which echoed the contribution of cultural heritage values to contemporary society.

\subsection{The "Future Education" between the Meaningful Landscape Narrative and Cultural Heritage Sustainability}

The meaningful landscape narrative is the public's understanding of the local cultural heritage status of historical sites, and is based on the landscape elements in Qing Yan Yuan. Although Qing Yan Yuan has undergone tremendous changes, the characteristics of the garden style are obvious and currently in a good state of preservation. It is well-known to the public that the scale of Qing Yan Yuan's construction is higher than that of private gardens, and the landscape elements combine the beauty of the south and the vigor of the north, thus forming a unique Jianghuai garden. In addition, because it was also used as the office and living place of Canal Governor-Generals, it is recognized by the public as a symbol of the water transport officials' garden. The Huai'an Water Transport Culture Museum was constructed at the exit of Qing Yan Yuan to display the location and frequency of floods during the Ming and Qing Dynasties; the widespread water control techniques used at that time, such as sluice models; and the models of emperor and ministers who have inspected the flood. Analyzing the data shows that the public visit the ruins of Qing Yan Yuan that are associated with the past to learn about the contribution of the garden to history, and these landscape experiences have enriched the personal background knowledge of the local cultural heritage. In addition, these landscape narratives have become the image of Huai'an history, which is conducive to future generations, whether they are familiar with it or not. It is also helpful to understand the local cultural heritage value to learn the knowledge of the water transport culture. Therefore, the interpretation of the landscape architecture site formed by the public who uses the landscape narrative materials is a form of cultural heritage education, which is beneficial to the present and future-oriented, and contributes to the sustainable management of cultural heritage.

\section{Conclusions}

The management of cultural heritage is a top-down development model that is usually dominated by experts who propose suggestions to localities and residents. In addition, the study of cultural heritage preservation in the concept of the landscape is also undertaken from an expert perspective. However, expert-based assessments cannot capture the dynamics and essence of social values. In particular, the public are the owners of the local cultural heritage and are thus more familiar with the stories of the heritage, while also having their own interpretation of cultural heritage values. Therefore, the public should not be passive in the preservation of the heritage. From a long-term perspective, sustainable cultural heritage management needs to be based on local areas and empower local populations, because personal knowledge and understanding are required to stimulate the public's awareness of heritage management.

This article adopts the landscape narrative method to systematically integrate the opinions of experts and non-experts, and analyzes how the public uses the experience of 
landscape observation to organize personal thinking in daily life. The study found that the local public established the identification strategy of Qing Yan Yuan as water transport cultural heritage through "originating landscape description, functional landscape description, and meaning landscape description". The original landscape narrative adopted by the local public is an expression of the "past presentation" that is based on recognizing the cultural heritage value; the functional landscape narrative is the embodiment of shaping cultural heritage value with "place identity"; and the composition of the meaningful landscape narrative is the symbolic spirit of local cultural heritage value. Thus, pride in the personal cultural heritage background is enhanced, and the realization of cultural heritage value via future education is promoted. From this perspective, the management of local cultural heritage value through the public who use the landscape narrative is conducive to establishing a sense of ownership and empowerment. This ownership is derived from personal experience and understanding, that is, the expression of the subjective thinking process to promote the local practice of cultural heritage sustainability.

The case study in this paper is Qing Yan Yuan in Huai'an, China, which is a site combining architecture and landscape, so the landscape narrative can explore the means by which the public describes the cultural heritage value. However, the promotion of this result requires architectural heritage with the same conditions. In addition, cultural heritage sustainability with the local public as the mainstay is an active heritage education learning method. Although the characteristics of origin, function, and meaning can help the public to interpret the connotations of local cultural heritage, researchers and heritage management departments can further explore how to mobilize the public to use the landscape narrative to spread the value of cultural heritage.

Author Contributions: D.F. contributed to the conceptual design of the study, data collection, drafting the article, formal analysis, and final approval. S.-c.C. contributed to the conceptual design of the study, supervision of the progress, and final approval. F.W. contributed to the conceptual design of the study, and data collection. All authors have read and agreed to the published version of the manuscript.

Funding: This research was supported by the Program of Jiangsu Social Science Foundation Youth Project in 2019 (No. 19YSC005), China. This research was supported by the project Program of Philosophy and Social Science Research in Jiangsu Universities in 2020 (No. 2020SJA1765), China. This research was also supported by the Program of National Natural Science Youth Fund Project Approval in 2018(No. 51808249), China. This research was also supported by Chinese Ministry of Education Project Approval in 2019(No. 19YJA760055), China.

Institutional Review Board Statement: Not applicable.

Informed Consent Statement: Informed consent was obtained from all subjects involved in the study.

Data Availability Statement: Not applicable.

Conflicts of Interest: The authors declare no conflict of interest.

\section{References}

1. The 17 Goals I Sustainable Development. Available online: https:/ / sdgs.un.org/goals (accessed on 23 March 2020).

2. Official Website of ICOMOS. Florence Declaration on Heritage and Human Values. In Proceedings of the 18th General Assembly, Florence, Italy, 12 November 2014. Available online: https://www.icomos.org/en/about-icomos/governance/generalinformation-about-the-general-assembly/list-of-general-assemblies/18th-general-assembly-florence-2014/9-uncategorised/ 429-18th-general-assembly-of-icomos (accessed on 21 August 2020).

3. Antrop, M. Why landscapes of the past are important for the future. Landsc. Urban Plan. 2005, 70, 21-34. [CrossRef]

4. Policy for the Integration of a Sustainable Development Percpective into the Processes of the World Heritage Convention. Working Document, Version. Available online: https:/ / whc.unesco.org/en/sustainabledevelopment/ (accessed on 5 September 2020).

5. Polglase, C.R. Cultural Heritage and Sustainability: Focusing on the Implementation Phase of Major Projects; United Nations Educational, Scientific and Cultural Organization: Paris, France, 2018; Volume 7, pp. 233-239. Available online: https://www.academia. edu/36139781/Cultural_heritage_and_sustainability_focusing_on_the_implementation_phase_of_major_projects (accessed on 20 September 2020). 
6. Cappa, F.; Rosso, F.; Capaldo, A. Visitor-Sensing: Involving the Crowd in Cultural Heritage Organizations. Sustainability 2020, 12, 1445. [CrossRef]

7. UNESCO. Introducing Cultural Heritage into the Sustainable Development Agenda. 2013. Available online: http://www.unesco. org/new/fileadmin/MULTIMEDIA/HQ/CLT/images/HeritageENG.pdf. (accessed on 30 November 2020).

8. Xia, J.; Chiou, S.C. On the Preservation of Cultural Heritage from the Perspective of "Landscape". Archit. Sci. 2016, 14, 29-53.

9. Jones, S. Wrestling with the Social Value of Heritage: Problems, Dilemmas and Opportunities. J. Community Archaeol. Herit. 2017, 4, 21-37. [CrossRef]

10. Edmond, M.; Ishanlosen, O. The question of heritage conservation and its sustainable development: Origins and the journey. In World Heritage for Sustainable Development in Aferica; Introduction; United Nations Educational, Scientific and Cultural Organization: Paris, France, 2018.

11. ICCROM: International Center of Studies for the Conservation and Restoration of Cultural Assets. People-Centred Approaches to the Conservation of Cultural Heritage: Living Heritage; Promoting People-Centred Approaches to Conservation (2011-2017); Rome, Italy. Available online: https://www.iccrom.org/sites/default/files/PCA_Annexe-2.pdf (accessed on 13 November 2020).

12. Yun, X.W.; Prott, L.V. Cultural revitalisation after catastrophe: The Qiang culture in a'er. Int. J. Herit. Stud. 2016, $22,26-42$.

13. Wang, R.; Liu, G.; Zhou, J.; Wang, J. Identifying the critical stakeholders for the sustainable development of architectural heritage of tourism: From the perspective of China. Sustainability 2019, 6, 1671. [CrossRef]

14. Wang, M.; Zhao, M.; Lin, M.; Cao, W.; Zhu, H.; An, N. Seeking Lost Memories: Application of a new visual methodology for heritage protection. Geogr. Rev. 2020, 110, 556-574. [CrossRef]

15. Egberts, L.; Schroor, M. Waddenland Outstanding: History, Landscape and Cultural Heritage of the Wadden Sea Region; Amsterdam University Press: Amsterdam, The Netherlands, 2018; p. 365. [CrossRef]

16. Lugeri, F.R.; Farabollini, P. Discovering the Landscape by Cycling: A Geo-Touristic Experience through Italian Badlands. Geosciences 2018, 8, 291. [CrossRef]

17. Pearson, M.; Sullivan, S. Assessing the value of Heritage places. The basics of Heritage planning for managers, landowners and administrators. In Looking after Heritage Places; Melbourne University Press: Melbourne, Australia, 1995.

18. Kim, U.E.; Triandis, H.C.; Kagitcibasi, C.E.; Choi, S.C.E.; Yoon, G.E. Individualism and Collectivism: Theory, Method, and Applications; SAGE Publications: Thousand Oaks, CA, USA, 1994.

19. Smith, L. The Uses of Heritage; Routledge: New York, NY, USA, 2006.

20. World Heritage Commission UNESCO. Climate Change and World Heritage. Electronic Document. Available online: http: //whc.unesco.org/en/climatechange/ (accessed on 12 January 2017).

21. Huang, M.Y. Cultural heritage and "place". China Cult. Relics 2009, 8, 43-47.

22. Norberg-Schulz, C. Genius Loci. Elespiritu del Lugar; Morar, R., Shih, C.M. (Trans.), Eds.; Garden City Publishing: Taipei, Taiwan, 1995; p. 23.

23. Diaz-Andreu, M. Heritage Values and the Public. J. Community Archaeol. Herit. 2017, 4, 2-6. [CrossRef]

24. Mei, Q. OUV Value of Gulangyu Cultural Heritage. In The Values of Gulangyu World Cultural Heritage; Springer: Singapore; Tongji University Press: Shanghai, China, 2020; pp. 13-50.

25. Qiu, Q.; Zheng, T.; Xiang, Z.; Zhang, M. Visiting Intangible Cultural Heritage Tourism Sites: From Value Cognition to Attitude and Intention. Sustainability 2020, 12, 132. [CrossRef]

26. Brundtland, G.H.; Khalid, M.; Agnelli, S.; Al-Athel, S.; Chidzero, B.J.N.Y. Our Common Future; Oxford University Press: New York, NY, USA, 1987.

27. The World Heritage Convention. Available online: https:/ /whc.unesco.org/en/convention/ (accessed on 17 November 2020).

28. Basu, A. Asmita Basu, Contexts and Concerns for Sustainability of Cultural Heritage Sites of Bishnupur. Plur. Hist. Cult. Soc. 2020, 8, 120-130. [CrossRef]

29. Polat, S.; Cahantimur, A.; Atanur, G.; Yıldız, H.Ö.T. A Quest for Sustainability of Cultural Heritage Sites: The Hanlar District of Bursa, Turkey. ICONARP Int. J. Archit. Plan. 2019, 7, 1-29. [CrossRef]

30. Jelincic, D.A.; Tisma, S. Ensuring sustainability of cultural heritage through effective public policies. Urbani Izziv 2020, 31, 78-87. [CrossRef]

31. European Convention on the Protection of the Archaeological Heritage (Revised). Available online: https://www.coe.int/en/ web / conventions / full-list/ - / conventions / treaty /143 (accessed on 6 October 2020).

32. Zan, L.; Baraldi, S.B.; Gordon, C. Cultural heritage between centralisation and decentralisation: Insights from the Italian context. Int. J. Cult. Policy 2007, 13, 49-70. [CrossRef]

33. Harvey, D.C. Heritage Pasts and Heritage Presents: Temporality, meaning and the scope of heritage studies. Int. J. Herit. Stud. 2001, 7, 319-338. [CrossRef]

34. Evans, G. Living in a World Heritage City: Stakeholders in the dialectic of the universal and particular. Int. J. Herit. Stud. 2002, 8, 117-135. [CrossRef]

35. Yung, E.H.; Chan, E.H. Problem issues of public participation in built-heritage conservation: Two controversial cases in Hong Kong. Habitat Int. 2011, 35, 457-466. [CrossRef]

36. Giannakopoulou, S.; Kaliampakos, D. Protection of architectural heritage: Attitudes of local residents and visitors in Sirako, Greece. J. Mt. Sci. 2016, 13, 424-439. [CrossRef] 
37. Grey, S.; Kuokkanen, R. Indigenous governance of cultural heritage: Searching for alternatives to co-management. Int. J. Herit. Stud. 2020, 26, 1-23. [CrossRef]

38. Bakri, A.F.; Ibrahim, N.; Ahmad, S.S.; Zaman, N.Q. Public Perception on the Cultural Significance of Heritage Buildings in Kuala Lumpur. Procedia Soc. Behav. Sci. 2015, 202, 294-302. [CrossRef]

39. Giannakopoulou, S.; Xypolitakou, E.; Damigos, D.; Kaliampakos, D. How visitors' value traditional built environment? Evidence from a contingent valuation survey. J. Cult Herit. 2017, 24, 157-164. [CrossRef]

40. Bergman, M.M.; Bergman, Z.; Berger, L. An Empirical Exploration, Typology, and Definition of Corporate Sustainability. Sustainability 2017, 9, 753. [CrossRef]

41. Franks, M.; Lessmann, K.; Jakob, M.; Steckel, J.C.; Edenhofer, O. Mobilizing domestic resources for the Agenda 2030 via carbon pricing. Nat. Sustain. 2018, 1, 350-357. [CrossRef]

42. Langellier, K.M. Personal narrative. In Encyclopedia of Life Writing: Autobiographical and Biographical Forms; Fitzroy Dearborn: London, UK, 2001; Volume 2, pp. 699-701.

43. Burke, K.A. Rhetoric of Motives; University of California Press: Berkeley, CA, USA, 1969.

44. Riessman, C.K. Narrative Analysis; Newbury Park, SAGE Publishings, Inc.: Washington. DC, USA, 1993.

45. Lothian, A. Landscape and the philosophy of aesthetics: Is landscape quality inherent in the landscape or in the eye of the beholder? Landsc. Urban Plan. 1999, 44, 177-198. [CrossRef]

46. Labov, W. Building on empirical foundations. Perspect. Hist. Linguist. 1982, $24,17$.

47. Meinig, D.W. The beholding eye: Ten versions of the same scene. In The Interpretation of Ordinary Landscapes: Geographical Essays; Oxford University Press: New York, NY, USA, 1979; pp. 33-48.

48. Clandinin, D.J. Narrative Inquiry: A Methodology for Studying Lived Experience. Res. Stud. Music. Educ. 2006, 27, 44-54. [CrossRef]

49. Holtorf, C.; Williams, H. Landscapes and Memories. Available online: https://howardwilliamsblog.files.wordpress.com/2018/0 4/holtorf-williams-2006.pdf (accessed on 17 October 2020).

50. van der Laarse, R. Gazing at Places We Have Never Been: Landscape, Heritage and Identity. In The Cultural Landscape and Heritage Paradox; Amsterdam University Press: Amsterdam, The Netherlands, 2010; pp. 321-328.

51. Smith, T.S.; Fiore, J.M. Landscape as Narrative, Narrative as Landscape. Stud. Am. Indian Lit. 2010, 22, 58-80. [CrossRef]

52. Chang, L.S.; Bisgrove, R.J.; Liao, M.Y. Improving educational functions in botanic gardens by employing landscape narratives. Landsc. Urban Plan. 2008, 86, 233-247. [CrossRef]

53. Feng, W. Landscape Narrative and Narrative Landscape-Reading Landscape Narrative: Storytelling Design Practice. Landsc. Archit. 2008, 2, 116-118.

54. Potteiger, M.; Purinton, J. Landscape Narratives: Design Practices for Telling Stories; John Wiley: New York, NY, USA, 1998.

55. Council of Europe. The European Landscape Convention. In Proceedings of the Europe Conference, Strasbourg, France, 20 October 2000. Available online: https:/ / www.coe.int/en/web/landscape (accessed on 10 August 2020).

56. Lowenthal, D. European landscape transformations: The rural residue. In Understanding Ordinary Landscapes; Groth, P., Bressi, T.W., Eds.; Yale University Press: New Haven, CT, USA, 1997; pp. 180-188.

57. Antrop, M. Sustainable landscapes: Contradiction, fiction or utopia? Landsc. Urban Plan. 2006, 75, 187-197. [CrossRef]

58. Ode, A.; Tveit, M.S.; Fry, G. Capturing landscape visual character using indicators: Touching base with landscape aesthetic theory. Landsc. Res. 2008, 33, 89-117. [CrossRef]

59. Downs, R.M.; Stea, D. Cognitive Maps and Spatial Behavior: Process and Products; John Wiley \& Sons, Inc.: Hoboken, NJ, USA, 1973; p. 25. [CrossRef]

60. Terkenli, T.S. Towards a theory of the landscape: The Aegean landscape as a cultural image. Landsc. Urban Plan. 2001, 57, 197-208. [CrossRef]

61. Lee, Y.J. The Relationships amongst Emotional Experience, Cognition, and Behavioural Intention in Battlefield Tourism. Asia Pac. J. Tour. Res. 2016, 21, 697-715. [CrossRef]

62. Antrop, M. The concept of traditional landscapes as a base for landscape evaluation and planning. The example of Flanders Region. Landsc. Urban Plan. 1997, 38, 105-117. [CrossRef]

63. Mascari, G.F.; Mautone, M.; Moltedo, L.; Salonia, P. Landscapes, Heritage and Culture. J. Cult. Herit. 2009, 10, 22-29. [CrossRef]

64. Cocks, M.; Vetter, S.; Wiersum, K.F. From universal to local: Perspectives on cultural landscape heritage in South Africa. Int. J. Herit. Stud. 2018, 24, 35-52. [CrossRef]

65. Apgar, J.M.; Ataria, J.M.; Allen, W.J. Managing beyond designations: Supporting endogenous processes for nurturing biocultural development. Int. J. Herit. Stud. 2011, 17, 555-570. [CrossRef]

66. Cocks, M.L.; Dold, T.; Vetter, S. 'God is my forest': Xhosa cultural values provide untapped opportunities for conservation. S. Afr. J. Sci. 2012, 108, 52-59. [CrossRef]

67. Ianni, E.; Rivera, E.S.; Geneletti, D. Sustaining cultural and biological diversity in rapidly changing communities: The revitalization of the Voladores ritual in northern Veracruz (Mexico). Environ. Dev. Sustain. 2014, 16, 1197-1208. [CrossRef]

68. Boley, B.B.; Johnson Gaither, C. Exploring empowerment within the Gullah Geechee cultural heritage corridor: Implications for heritage tourism development in the Lowcountry. J. Herit. Tour. 2016, 11, 155-176. [CrossRef]

69. Guilfoyle, D.R.; Carey, G.; Rogers, A.J.; Bernard, M.; Willoya-Williams, R. Empowering Tribal Youth in Cultural Heritage Management: A Case Study from the Kenai Peninsula, Alaska. Archaeologies 2019, 15, 42-63. [CrossRef] 
70. Sanoff, H. Community Participation Methods in Design and Planning; John Wiley \& Sons: New York, NY, USA, 2000.

71. Harvey, D.C.; Waterton, E. Landscapes of heritage and heritage landscapes. Landsc. Res. 2015, 40, 905-910. [CrossRef]

72. Gobster, P.H.; Nassauer, J.I.; Daniel, T.C.; Fry, G. The shared landscape: What does aesthetics have to do with ecology? Landsc. Ecol. 2007, 22, 959-972. [CrossRef]

73. Zhao, M.Q. The Formation of Canal Capital Huai'an and Its Historical Status. Jiangsu Local Hist. 2016, 4, 39-43.

74. Wang, S.H. Analysis of the Historical Status and Function of the Grand Canal in Huai'an Based on Archaeological Data. Identif. Apprec. Cult. Relics. 2007, 7, 58-59.

75. Gu, J.G. Local Culture History of Jiangsu—Huai'an Volume; Zhu, X.Y., Zhou, X.Y., Eds.; People's Publishing House: Nanjing, China, 2019.

76. Guan, X.; Tao, S. Huai'an Water Resources Project Rooted in Local Water Culture. In Proceedings of the 1st China Water Culture Forum, Jinan, China, 13 November 2009; China Water \& Power Press: Beijing, China, 2009; pp. 404-411.

77. Huai'an Civil Affairs Bureau, Huai'an Historical and Cultural Research Society. History of Huai'an Place Names; Zhonghua Book Company: Beijing, China, 2015.

78. Lincoln, Y.S.; Guba, E. Naturalistic Inquiry; Sage: Thousand Oaks, CA, USA, 1985.

79. Patton, M.Q. Two decades of developments in qualitative inquiry: A personal, experiential perspective. Qual. Soc. Work 2003, 1, 261-283. [CrossRef]

80. Coffey, A.; Atkinson, P. Making Sense of Qualitative Data: Complementary Research Strategies; SAGE Publications: Thousand Oaks, CA, USA, 1996.

81. Kirk, J.; Miller, M.L. Reliability and Validity in Qualitative Research; Beverly Hills, SAGE Publications: Thousand Oaks, CA, USA, 1986. [CrossRef]

82. Strauss, A.; Corbin, J. Basics of Qualitative Research Techniques; SAGE Publications: Thousand Oaks, CA, USA, 1998.

83. Cresswell, T. Place: A Short Introduction, 2nd ed.; Wiley-Blackwell: Chichester, UK, 2014.

84. Zhao, E.X. Manuscripts of the Qing Dynasty; Shanghai Ancient Books Publishing House: Shanghai, China, 1986; Volume 116, p. 3341.

85. Gao, C.M.; Hu, Z.Z. Annals of Huai'an Mansion in Kangxi. Kangxi Edition in Qing Dynasty. Available online: http://www. xianzhidaquan.com/product.php?id=4223 (accessed on 22 May 2020).

86. Li, W. The History of Yangzhou, Chapter 2. Available online: http://www.xianzhidaquan.com/product.php?id=7237 (accessed on 30 May 2020).

87. Wang, H.D. Lakes of China; The Commercial Press: Shanghai, China, 1995; pp. 105-106.

88. Xun, D.L. The Formation and Transmutation of the Canal City. Jiangsu Local Hist. 2006, 4, 34-39.

89. Gao, B. The Collected papers of Gu Zai Cao Tingg; 24th Edition of Qianlong of Qing Dynasty. Available online: https://ctext.org/ wiki.pl?if=gb\&chapter=714384 (accessed on 15 June 2020).

90. Wei, Z.Z. Revised, Annals of Huai'an History of Qianlong; Engraving Version of the 13th Year of Qianlong, Qing 1149 Dynasty. Available online: https: / / ctext.org/wiki.pl?if=gb\&res=741707 (accessed on 27 May 2020).

91. Wan, Y.L.Q.; Wang, C.Q. Hongxue Karma (2), Qingyan yuan and Blessings, Appointing Snow in the West Garden; Zhejiang People's Fine Arts Press: Hangzhou, China, 2011; pp. 514-542.

92. Wu, T.X. Annals of Qinghe History; Published in the 8th year of the Republic of China. Available online: https://ctext.org/ library.pl?if=gb\&file=122284\&page $=1$ (accessed on 20 June 2020).

93. Ji, Z.Y. Shi Shantang's Anthology of Poems; Published in the Third Year of Jiaqing Dynasty. Available online: https://ctext.org/ wiki.pl?if=gb\&chapter $=606521$ (accessed on 26 June 2020).

94. Zhang, K.F. A Study on the Construction of Canal Governor-Generals in the Qing Dynasty. Hist. Teach. 2008, 9, 100-104.

95. Zheng, M.D. The Evolution, Functions, Power Game and River Disadvantages of River Administrators in Qing Dynasty: An 1157 Investigation from the Perspective of Jiangnan Canal Governor-Generals. J. Yibin Univ. 2012, 12, 32-37.

96. Liu, D.Z. Suzhou Classical Garden; China Architecture \& Building Press: Beijing, China, 1979.

97. Zhuang, X.F.; Liu, H. A Preliminary Study on the Hierarchy of Ancient Chinese Architecture. Pop. Sci. 1160 Technol. 2005, 7, 169.

98. Xiang, Y.S. On the Influence of Ritual System on Chinese Ancient Architecture; Shanxi Architecture: Shanxi, China, 2009 ; pp. 35-36.

99. Cai, W.G. The Garden of Ming and Qing Dynasties and Its Compatible with North and South Cultures-An Analysis of 1164 Qing Yan Yuan Art in Huai'an City. Landsc. Arch. 2019, 6, 40-44.

100. $\mathrm{Wu}$, H.Q. The Regional Distribution of Imperial Palaces in Sui and Tang Dynasties. Collect. Diss. Chin. 1166 Hist. Geogr. 1994, 2, 71-85.

101. Jie, Y.Q. Study on the Palace of the Guanzhong Tang Dynasty. Collect. Essays Chin. Hist. Geogr. 2000, 3, 197-212.

102. Qi, Y.H. The research on Li-gong and Xing-gong. China J. Xi'an Univ. Arts Sci. Soc. Sci. Ed. 1170 2010, 2, 4-6.

103. Zuo, B.Q. Qianlong's Southern Tour. China J. Palace Mus. 1981, 2, $22-37$.

104. Xu, K.; Shang, Q. Emperor Qianlong's Southern Tour and River Control. J. Peking Univ. Philos. 1173 Soc. Sci. Ed. 1990, 6, 12.

105. Xi, H.D.; Gao, B. Study on the Illustration of the South River and Qianlong's First Southern Tour. Chin. Hist. Geogr. 2012, 27, 132-142.

106. China: Records of Emperor Gaozong of the Qing Dynasty; Chapter 249. Available online: https://www.zhonghuadiancang.com/ lishizhuanji/daqinggaozongchunhuangdishilu/97230.html (accessed on 3 June 2020). 
107. Gao, J. Southern Tour Grand Ceremony chapter 43, River Defense, Entropy of the Hall of Martial-Valor in the 36th Year of 1178 Emperor Qianlong's Reign (1771). Available online: https: / ctext.org/wiki.pl?if=gb\&chapter=446188 (accessed on 17 June 2020).

108. Zhu, Y.S. The West Garden of the Cao Canal Governor-Generals in the Ming and Qing Dynasties. Chin. Landsc. Arch. 1180 1994, 1, 17-20.

109. Hua, H.J.; Jin, H.X. The Aesthetic Value of Calligraphy in Chinese Classical Garden. J. Zhejiang For. Univ. 1182 China 1998, 1 , 316-319.

110. Du, Y. On the Origin and Characteristics of Stele Inscription. Lantai World 2008, 9, 78.

111. Huang, Z.L.; Yang, S.F. An overview of Buddhist tablet inscriptions in Yunnan. J. Dali Univ. 2015, $1185,14$.

112. Wang, F.X. On the Expression of Artistic Conception in Chinese Classical Garden. Chin. Landsc. Arch. 2004, 1187, 43-44.

113. Gu, L.R.; Xu, X.S. Design of Garden Road in Landscape Architecture. Anhui Agric. Sci. 2007, 1189, 64-69.

114. Xiao, F.; Zhang, X.L. Interesting Stories of Jiangsu; Tourism Education Press: Beijing, China, 2007.

115. Zhou, W.Q. History of Chinese Classical Gardens; Tsinghua University Press: Beijing, China, 1999.

116. Sun, L. An Analysis of the Name of Chinese Garden. Archit. Cult. 2016, 11, 192-193.

117. Wang, X.H. Nomenclature and Taoist Meaning of Jiangnan Landscape Architecture. J. Univ. Sci. 1194 Technol. Beijing 2008, 24, 164-168.

118. Ji, X.M. Annals of Qinghe County, Xianfeng; Culture and History Press: Beijing, China, 2017.

119. Gong, Z.; Xiao, Y. The Perfect Scenic Spot with Northern and Southern Amorous Attrition-Qing Yan Yuan. Famous 1197 City Paint. China 2014, 4, 74-76. 